\title{
EC-Seal Products: Seals and Sensibilities (TBT Aspects of the Panel and Appellate Body Reports)
}

\author{
PHILIP I. LEVY* \\ The Chicago Council on Global Affairs and Northwestern Kellogg School of Management \\ DONALD H. REGAN* * \\ University of Michigan Law School
}

\begin{abstract}
The EC-Seal Products case stemmed from complaints by Canada and Norway against European Union regulations that effectively banned the importation and marketing of seal products from those countries. The EU said it had responded to European moral outrage at the killing of seals. Canada and Norway challenged the regime under various provisions of the Technical Barriers to Trade (TBT) Agreement and the GATT. This article considers TBT aspects of the Panel and Appellate Body decisions. It discusses issues such as whether there is any bright line to be drawn between legitimate and illegitimate purposes in regulation, the proper legal meaning of a 'technical regulation', and the interpretation of TBT 2.1.
\end{abstract}

\section{Introduction}

European Communities - Measures Prohibiting the Importation and Marketing of Seal Products ${ }^{1}$ involved complaints by Canada and Norway against European Union regulations that had the effect of banning the importation and marketing of seal products in the EU. The EU said it enacted the ban in response to European moral outrage at the inhumane killing of seals, and to avoid participation in such inhumane killing by the purchase of seal products. The EU claimed a general ban was necessary, as opposed to a ban solely on products from seals killed inhumanely, because it would be impossible to monitor effectively whether particular seals were killed inhumanely on seal hunts. Three categories of seal products were excepted from the ban: products from seals killed in traditional hunts by members of indigenous communities such as the Inuit (the 'IC exception'); products from seals killed in hunts authorized by national governments for marine resources

\footnotetext{
*Email: plevy@thechicagocouncil.org.

**Email: donregan@umich.edu.

1 WT/DS400 \& 401/R (adopted as modified 18 June 2014).
} 
management (the 'MRM exception'); and products brought in by travelers for their own use (the 'Travelers' exception').

Canada and Norway challenged the EU seal products regime under various provisions of the Technical Barriers to Trade (TBT) Agreement and the GATT. Aside from the threshold TBT issue of whether the regime was a technical regulation, the principal issues under both agreements revolved around whether the EU's various purposes were legitimate, whether they were evenhandedly applied, and whether the general ban on seal products was unnecessarily trade-restrictive. The Panel found that the measure was a technical regulation within the meaning of TBT Annex 1.1, and that both the IC exception and the MRM exception violated TBT 2.1. The Panel also found a violation of TBT 5.1.2, first sentence, as well as violations of GATT I:1 (the IC exception) and III:4 (the MRM exception). The Appellate Body has already decided the appeals from the Panel's decision. ${ }^{2}$ The Appellate Body found that the measure was not shown to be a technical regulation, and declared the Panel's discussion of particular TBT violations 'moot and of no legal effect'. The Appellate Body then confirmed the GATT I:1 violation, although on somewhat different reasoning from the Panel. (The EU did not appeal the Panel's finding of a III:4 violation.)

This essay comprises two principal sections, Section 2 on economic considerations, and Section 3 on the legal issues. Of course, it is the premise of this entire series of case reports that there is no essential conflict between the economic and legal perspectives, and that a unified presentation should be possible in principle. Both co-authors accept that premise. But regardless of disciplinary background, people can disagree about how tribunals should approach cases such as EC-Seal Products, about the relative dangers of protectionism and undue restriction of legitimate regulation; and we have not achieved sufficient agreement between ourselves to allow a unified presentation. So by default, each author has tended to his own disciplinary last, with input from the other.

Section 2 attempts to describe a general framework for thinking about conflicts between the right to regulate and rights of market access. One of the most interesting aspects of the case is the extent to which the EU concern was based on the sentiments of its citizenry about economic activity occurring in other countries. Section 2 considers different economic approaches to consumer welfare and asks whether there are any bright lines that can be drawn between different justifications for regulation. Section 2 also considers how we might use the economic theory of screening equilibria in trying to identify regulations motivated by illegitimate national-origin preferences. Finally, Section 2 takes up the economic theory of incomplete contracting and time-inconsistency, to discuss the effect on trade negotiations of uncertainty about how treaty language will be interpreted by dispute settlement tribunals; and it asks whether there are lessons for the treaty interpreter. 
Section 3, on the legal issues, faces a special problem, which also turns out to be an opportunity. The general plan of this series of case discussions requires that we should discuss the Panel report, and leave the Appellate Body report for discussion next year. That seems quixotic enough. In addition, the Panel's main focus was on the TBT; its treatment of the GATT issues was parasitic on its TBT analysis. But, as noted above, the Appellate Body found that the measure was not shown to be a technical regulation (reversing the Panel on that), and declared the Panel's discussion of particular TBT violations 'moot and of no legal effect'. In Section 3, we will discuss the TBT issues (and only the TBT issues) at both the Panel and Appellate Body levels. We will discuss both the Panel's analysis and the Appellate Body's analysis of whether the EU seal products regime is a technical regulation; and we will then discuss the Panel's analysis of the other TBT issues (which the Appellate Body does not address). Even though the Panel's TBT analysis has no legal effect, it is nonetheless the first discussion we have by a WTO tribunal of important TBT issues that will certainly arise again. We will not discuss the GATT issues at either the Panel or Appellate Body level. The Panel's GATT analysis has not been declared moot across the board, but it has been largely superseded by the Appellate Body's treatment, which we leave for discussion next year.

\section{Economic considerations}

From an economic standpoint, the most interesting facets of the case include the plausible scope of individual and societal preferences, screening equilibria, and incomplete contracting. The case revolved around the EU contention that the sale of seal products within the European market would pose a threat to European morals. Curiously, throughout the argumentation, there was relatively little dispute about this assertion. There were disputes aplenty, to be sure, but they tended to revolve around which line of legal reasoning would arrive at this conclusion, and in turn, what requirements the ultimate legal approach would impose on the EU's devotion to its cause, and the actions the EU would take.

In a prescient analysis from $1997,{ }^{3}$ Charnovitz discussed the concept of morality in international trade law. He noted that clauses in trade agreements had made allowances for measures in support of public morals from the 1920s and earlier. The explicit GATT provision, Article XX(a), thus had a long provenance, but had yet to be explored or fleshed out through dispute settlement. ${ }^{4}$ The EC-Seal Products case marks at least the opening round of that exploration.

3 Steve Charnovitz (1997), 'Moral Exception in Trade Policy', The Virginia Journal of International Law, 38: 689 .

4 Although there is no previous jurisprudence on GATT XX(a) itself, the discussion of GATS XIV(a) in United States - Measures Affecting the Cross-Border Supply of Gambling and Betting Services (Antigua and Barbuda), WT/DS285/R (adopted 22 May 2007) is generally thought to be relevant. 
In the dispute, the question of whether the EU seal regime denied Canada and Norway their rights under TBT or under GATT took center stage. Here, though, we shunt it aside and focus instead on how one might think of the case in terms of some of the first principles of economics, such as preferences and consumption. That leads to some more subtle topics, such as imperfect information and bargaining. In deliberate contrast to a legal approach, we consider these matters afresh, without worrying about precedents or judicial interpretations. The goal is to make a connection between conceptual approaches and likely outcomes. Particularly on a topic that is being freshly litigated, the hope is that this approach will provide, if not a guide, at least a yardstick against which the legally mandated approaches can be measured.

A core question in the EC-Seal Products case is the extent and character of EU concerns over Canadian and Norwegian seal hunts. Section 2.1 asks whether there are natural bright lines that separate the legitimate topics of national concern from illegitimate topics. For that section, we stipulate purity of motive on the part of the EU. Section 2.2 relaxes the purity assumption and considers the quest for a separating equilibrium which might distinguish the purely motivated from the impurely motivated. Section 2.3 sets aside questions of the legitimacy of motivation and steps back from the particular questions of seals and morality to ask what happens if we observe shifts in the scope of rights and obligations over time.

\subsection{Bright lines and hakapiks}

\subsubsection{Introduction}

What are the proper bounds of a country's regulatory powers? If countries are allowed to lay out the permissible characteristics of a product, what do we mean by 'characteristics'? As a means of addressing these questions, this section establishes a basic framework that we will later complicate. Throughout this section, we assume that there is homogeneity of preferences among a national population. In economic parlance, one could discuss a representative agent with utility $\mathrm{U}(\bullet)$, where all of the debate will be over the implications of placing ever-broader arguments in the utility function. In political terms, we will assume that these individuals have an actual representative agent (government) with no motive other than to maximize the population's well-being (the discounted stream of utility payoffs over time).

We progress from narrow, uncontroversial determinants of well-being to broader, more arguable ones. At each stage, we stop to take note of the measurability of the product characteristics in question, any natural limitations on the scope of individuals' concerns, and on the potential for international conflict. This is done in anticipation of disputes further down the line, when we return to worrying about more legal matters like establishing a practicable set of rules. The goal is to see whether there are clear delineations between different motivations for government action. It is an attempt to classify motives by the way something enters into a national welfare function. 
Before delving in, it may be worth taking a moment to look at the concept of 'natural limitations'. This is not a reference to any sort of divinely ordained categorization. Rather, it is looking for qualitative differences in approach. Of course, there is nothing that restricts the WTO membership to one category or another as it describes the limitations on countries' rights to impose trade barriers. But subtle, quantitative distinctions usually require explicit delineation in agreements in a way that broad, categorical distinctions do not. Thus, if the Dispute Settlement Body is in search of safe havens to find consistency in rulings, such havens are more likely to be found at these categorical boundaries.

The presumption is that there may be a desire to stop short of extreme territoriality. There are two broad checks on the potential for capricious trade restrictions - the motive must be one that the WTO membership has approved, and the implementation of the measure must meet particular requirements (e.g. least trade restrictive). ${ }^{5}$ If governments can act with impunity on any moral indignation of the citizenry, and that indignation can have any cause (e.g. educational curricula in Timbuktu), then the first of these two checks becomes meaningless. ${ }^{6}$

We proceed through three different categories. First, preferences over the physical characteristics of a product. Second, preferences over the pedigree of a product (how it was made). Third, moral sentiments, potentially disconnected from a product altogether. These are not mutually exclusive, but represent steadily broader domains of concern.

\subsubsection{Preferences over a product}

In the most standard approach to economics, we think of consumers drawing utility from the consumption of a good. A diner consumes some swordfish and is happier for it. We can also think of disutility in consumption - someone consumes a dose of mercury and is distinctly worse off for it. Here, then, we get to an obvious scenario for regulation: if the swordfish contains mercury, this will have a direct effect on the consumer's well-being. If it were immediately obvious to the naked eye whether swordfish contained mercury or not, though, there might not be a need for regulation. There would presumably be little market for tainted fish. More likely, though, is the possibility that it is costly to check the characteristics of the product. Rather than make individual customers check fish themselves, a regulator could require and enforce rules that represented public tastes.

When describing the physical characteristics of products, measurability is at its easiest. One can test to see how much mercury is in the swordfish. The ready observability of physical characteristics does not render such preferences immune from TBT.

5 This generalization abstracts from potential differences between restrictions under the GATT and

6 This seems to be a principal source of division between those who are more or less concerned about an expansive interpretation of the 'moral exceptions' clause. Those who are comfortable with backup protections against capriciousness are less concerned about allowing a broad range of motives. 
conflict. While one can observe the physical characteristics, there could be disputes over the relevance of those characteristics. A classic example would be genetically modified organisms (GMOs). Their presence can be measured, but what of their impact on health? From a trade perspective, under our strong assumption of homogeneity of tastes, it should not make much difference. If everyone in a country believes that GMOs pose an unacceptable health risk, there will be no market for products containing GMOs. ${ }^{7}$ Thus, even if another country had a very different view of the health effects, a non-discriminatory ban on the product would be unnecessary. As foreshadowing for looser assumptions in Section 2.2, this issue will reemerge as a major problem with heterogeneity of preferences, under which one group believed GMOs were risky and another thought them safe. As far as measurability is concerned, the bottom line is that the physical characteristics could be readily verified, even if the medical implications could not.

Thus, the simplest argument of the utility function is direct consumption of a product. We can also consider indirect consumption of a product, when the consumption undertaken by a fellow countryman has positive or negative externalities. Classic examples could include second-hand smoke or garish house paint, each of which could provide pleasure to the original consumer but displease a compatriot. Such externalities provide a well-established basis for regulation, since individual welfare maximization could lead to a suboptimal outcome. Because we are talking about the effects of physical characteristics (drifting smoke, visible color), measurability is not much of a problem here. One certainly could encounter international disputes in instances in which it appeared that 'like' products with similar negative effects were being treated differently. This was part of the claim in US-Clove Cigarettes, in which it was argued by Indonesia that clove and menthol cigarettes had similar effects, while the United States argued that their physical characteristics were distinct. ${ }^{8}$

We conclude the discussion of physical characteristics with a consideration of the natural limitations on the scope of this type of regulation. The regulations would cover the physical characteristics of goods sold in the imposing country. As an importer, the country need take no stance on how the goods achieved their physical state. So long as the relevant physical characteristics were measurable, there would be no reason for concern about how the product came to be that way. We note this as a baseline to contrast with broader concerns to come. We also note that, while drawing a bright line at observable physical characteristics might be well-grounded

7 So as not to take on every conceivable point of conflict, we set aside questions about the cost of informational regulation (e.g. country of origin or content labeling) and assume that regulators could make clear the contents.

8 United States - Measures Affecting the Production and Sale of Clove Cigarettes (Indonesia), WT/ DS406/AB/R (adopted 24 April 2012). For a detailed discussion, see Broude et al. (2014), 'Do you mind if I don't smoke? Products, purpose and indeterminacy in US-Measures Affecting the Production and Sale of Clove Cigarettes', World Trade Review, 13(2): 357-392. 
in economic tradition, this approach has previously been rejected by the Appellate Body in US-Shrimp 21.5.9

\subsubsection{Preferences over process}

We turn next to considerations about how a product was made. While this category could potentially be quite broad, we will intentionally narrow it by directing large swathes toward the preceding and following categories. One central issue that will fall into this category is negative production externalities. Suppose a product could be made with either a 'dirty' or a 'clean' technique. The dirty technique might release significant pollution, while the clean technique releases none. If this pollution occurs within our regulating country, or sufficiently nearby that the country suffers the consequences, it can certainly affect the welfare function of individuals within. The government would have the sovereign right to regulate any domestic production, but what about the production of goods that ultimately end up as imports? The effectiveness of regulation in promoting domestic welfare will now depend on a two-stage process - the way regulation affects domestic consumption and the way changes in domestic consumption affect the quantity of pollution spillovers. ${ }^{10}$

In terms of measurability, the challenge here is substantially greater than in the previous section. It may be relatively straightforward to measure the extent of pollution flowing across the border from a neighboring country, but how much of that pollution is due to production of the product in question? If we assume that the output of the dirty and the clean techniques are indistinguishable, then this poses a significant difficulty for customs. We could hypothesize two different products differentiated by the characteristic 'how they were made'. ${ }^{11}$ Since that characteristic is not physical nor visible at a customs entry point, any difference in regulatory approach would either require an erroneous approximation or cooperation on the part of the exporter. Either approach would heighten the possibility of international conflict - either unjustified blockage of a product, or potential interference in the domestic practices of another country.

Still, by requiring a measurable negative externality, there are limits to the scope of such concerns. For example, while one might be tempted to equate this concern with 'processes and production methods' (PPM), ${ }^{12}$ the overlap is imperfect.

9 United States - Import Prohibition of Certain Shrimp and Shrimp Products (India; Malaysia; Pakistan; Thailand), WT/DS58/AB/R (adopted 6 November 1998), Article 21.5.

$10 \mathrm{We}$ are assuming here that regulation is limited to working through effects on domestic consumption, as opposed to through adopting penalties that might alter the behavior of foreign producers who also had interests within the country or through attempting to influence foreign governments.

11 A point of disagreement between the AB and the Panel in EC-Seal Products concerned whether such production history counted as a 'product characteristic' or not. The Panel said yes; the AB said no. It was a distinction critical to whether the EU Seal Regime counted as a technical barrier to trade (Panel) or not $(\mathrm{AB})$.

12 This is dealt with in Section 3.1 below. 
Organic farming, for example, would not fall into this category. While it could well affect the presence of pesticides in food, that concern would properly fall into the previous category - the physical characteristic of containing pesticides. The method would only serve as an imperfect proxy for the true concern. ${ }^{13}$ Similarly, this would not encompass concerns such as those of the EU over an inhumane seal hunt. In the arguments put forward in EC-Seal Products, there was no allegation that Canadian or Norwegian practices inflicted physical harm through negative spillovers. The alleged harm was psychic - a moral offense. Thus, those concerns properly belong in the next category.

\subsubsection{Moral offense}

This section, in contrast to the familiar analysis of the preceding sections, takes on the relatively novel question of how to consider moral offense in utility. This is the unchallenged core of the EC-Seal Products case. According to the EC, Europeans found the inhumanity of seal hunting repugnant and immoral. It pained them just to know that it occurred. This was not disutility from the consumption of seal products such as furs or sealskin boots. Nor was it any environmental spillover from the killing of seals, as one might have if they were migratory and played a key role in a European food chain. Instead, the Europeans argued that commercial seal hunts were inevitably inhumane and morally offensive.

There is nothing unusual about members of a community setting standards for right and wrong. Traditional concepts of sovereignty provide a natural limitation on the scope of such standards - communities can set the rules under which they live. There are also traditions of supra-national efforts to establish standards with much broader reach, as with the United Nations, the International Labor Organization, or the WTO. In such cases, there is a degree of international consensus about what the standards should be.

The oddity of the claim of moral offense in EC-Seal Products is that there is very little natural limitation to its reach. It reaches across boundaries, but requires no international consensus. The principal test for legitimacy of a 'public morals' claim under GATT Article XX(a) seemed to be the sincerity of public sentiment. Such a test presumably protects against completely spurious claims, such as 'My people are morally offended by the use of minimills to produce cold-rolled steel!' But there are many plausible topics on which public sentiment would likely pass a sincerity test. Maskus ${ }^{14}$ summarizes a debate over the extraterritorial enforcement of labor standards. He describes first the position of Dani Rodrik, who advocated

13 In legal parlance, the distinction is between 'incorporated PPM's' (where the process affects the physical constitution of the product) and 'unincorporated PPM's' (where it does not). Only the latter are controversial.

14 Keith Maskus (1997), Should Core Labor Standards be Imposed Through International Trade Policy, Policy Research Working Paper No. 1817, Washington, DC: World Bank. 
allowing nations to impose 'social safeguards' tariffs against countries that follow labor practices that can be shown, through a series of filters, to be morally reprehensible to a majority of citizens in the importers. His argument is that high-standard countries, such as the United States, have expressed in their legislation social preferences against certain domestic production technologies, such as child labor use and 'sweat shops'. However, allowing free imports with low-standard countries is, in his view, simply an additional technology that is equivalent to importing foreign workers and allowing them to work under these unacceptable conditions. Accordingly, importing nations should be allowed to prevent access to this technology as well via trade restrictions.

Maskus quotes T. N. Srinivasan as critiquing the idea:

acceptance of this proposal would pose considerable difficulties for the trading system. Apart from technical difficulties in calculating appropriate social tariffs, its logic would open the WTO to trade sanctions imposed by countries for any purpose related to cost-raising domestic regulations. Countries constrain or prohibit numerous types of processes for environmental, health, aesthetic, and other reasons. Under Rodrik's approach, any such differences in domestic and foreign production regulations potentially could invite tariffs to offset resulting cost variations.

Note that Srinivasan's argument, as quoted, presumes a limitation that need not exist in the public morals setting. He imagines that there must at least be a linkage between foreign practice and domestic costs. With public morals, there need be no such linkage. The public could be offended by multinationals linked to imperialism, or by countries with objectionable human rights records. All that seems required is a sincere belief that the act is offensive and commerce would, directly or indirectly, support the act.

In his consideration of the GATT public morals clause, Charnovitz finds relatively few limitations. He writes:

The danger of protectionist abuse is real. Virtually anything can be characterized as a moral issue. At this point, however, it seems premature to worry about overuse of article $\mathrm{XX}(\mathrm{a})$. One can imagine nations justifying many import bans as morally based. Throughout the 50 years of the GATT-WTO system, however, no member state has challenged a morally based import ban. ${ }^{15}$

That last consolation, of course, no longer applies. In his invocation of protectionist danger, Charnovitz raises the specter of mixed motives, which we have deferred to the following section.

The point here is the potential breadth of moral claims. The potential for extraterritoriality and overreach has drawn dramatic speculative examples from other authors, particularly in the analyses of the US-Gambling decision, which relied

15 Steve Charnovitz (1998), 'The Moral Exception in Trade Policy', The Virginia Journal of International Law, 38(Summer): 21. 
on the analogous GATS Article XIV(a). Marwell attributes the growing challenge of limiting public morals cases under the GATT to the burgeoning membership of the organization:

Amongst 148 WTO Member States, 'public morals' could mean anything from religious views on drinking alcohol or eating certain foods to cultural attitudes toward pornography, free expression, human rights, labor norms, women's rights, or general cultural judgments about education or social welfare. What one society defines as public morals may have little relevance for another, at least outside a certain core of religious or cultural traditions. ${ }^{16}$

$\mathrm{Wu}$, in his analysis of US-Gambling, provides a trichotomy of potential public morals measures:

Type I restrictions are those used to directly safeguard the morals of inhabitants within one's own country. The US ban on internet gambling would fall into this category, as would bans on pornography, narcotics, or alcohol. Type II restrictions are those linked to the protection of those directly involved in the production of the product or service in the exporting state. For example, a ban on products made by child labor would fall within this category, as would a ban on services for sex tourism. Type III restrictions are those aimed at products or services produced in an exporting state whose practices are considered morally offensive by the importing state, but where the practices are not directly involved in the production of the products or service being banned. An example would be an outright ban on imports from Sudan because of its government's human rights violations in Darfur. ${ }^{17}$

Wu goes on to recommend that a natural limitation on morals measures would be to limit countries to Type I restrictions. This typology matches only imperfectly with one based on an economic welfare approach. In the Type I examples given in the quoted paragraph-gambling, pornography, narcotics, or alcohol-we think of the harm as deriving from either an individual's consumption or the negative spillovers of the consumption of others in the community. Such a narrow reading of Type I moral concerns would effectively take us back to the types of welfare analysis described before this section. In Wu's typology, seal hunting should properly fall within Type II. However, the EU claim, if taken seriously, is that EU consumers suffer moral harm from purchasing the products of seal hunts. If the moral harm is psychic in this way, rather than through consumption, and if states have the right to try to alleviate this harm, then it is hard to see why it matters whether the sincere moral offense stems from a production process or from

16 Jeremy C. Marwell (2006), 'Trade and morality: The WTO public morals exception after gambling', New York University Law Review, 81: 802, at 815.

17 Mark Wu (2008), 'Free Trade and the Protection of Public Morals: An Analysis of the Newly Emerging Public Morals Clause Doctrine', The Virginia Journal of International Law, 33: 215, at 235. 
dealing with an individual, company, or country that the morally sensitive inhabitants of the importing country find objectionable.

This moral category of welfare claim poses commensurate challenges when it comes to measurability. Though a trade measure would necessarily apply to a good or service imported from another country, there need be no observable characteristic of that product to reveal whether it should be subject to the measure. Nor would there need to be any observable transboundary flows of pollution or other diminished migration.

In fact, the measurability problem runs even deeper. One of the questions raised in the EC-Seal Products case was whether the EU seal regime served to ameliorate the problem. If the 'problem' were the Canadian or Norwegian seal hunts, then evidence of the sort presented in the Panel decision ${ }^{18}$ should suffice. But the EC-Seal Products case is emphatically not about animal welfare, which would be covered under GATT Article XX(b). The Panel writes: 'Based on the examination of the measure at issue as well as other available evidence before us, we determined that the objective of the EC Seal Regime was to address the EC public moral concerns on seal welfare. ${ }^{19}$ We further found this objective to fall within the scope of the policy objective governed by Article XX(a).'20

The extent of public moral concern is substantially more difficult to measure. Nor is it obvious that such a psychological measure would vary (strongly) monotonically with more observable measures, such as the number of seals hunted. If we fielded a survey across the EC, for example, which asked the public how upset they were about seal hunting on a scale of 1 to 10 , we might well get the same level of moral concern in a year in which 400,000 seals were killed as in a year in which 100,000 seals were killed. There would be nothing irrational or ignorant about such a finding; an EU citizen could feel strong outrage if even one seal were killed and need not reserve additional levels of outrage for higher death tolls. Technically, though, this demonstrates both that the problem (moral concern) is exceedingly difficult to measure, and that actions to diminish the subject of concern need not diminish the moral concern itself.

\subsubsection{Attempts at limitations}

Does the breadth of a moral concerns approach to welfare mean that one should forsake it altogether and that it should be impossible to restrict trade based on the characteristics of the production process? No. There can be processes that everyone agrees are offensive (e.g. slave labor). If the objections are universal, then there should be no difficulty agreeing to embody them in explicit

18 Para. 7.457.

19 See Section 7.3.3.1 above.

20 Para. 7.640 . 
exemptions. ${ }^{21}$ Both Marwell and Wu explore potential limitations based on the extent of global support for a moral standard. There are a number of difficulties, however. Wu notes that geopolitical measures against Taiwan or Israel frequently garner sufficient support to clear any standard majoritarian hurdle. ${ }^{22}$ From a systemic standpoint, if the moral standards themselves are not accepted by all WTO members, then anything short of unanimity would represent a de facto move to a new majority voting standard. Extensive experience at international organizations such as the United Nations or the International Monetary Fund demonstrates that countries care deeply about the weights and requirements in any such scheme. ${ }^{23}$ Obviously, in a contested dispute such as EC-Seal Products, there is no consensus about the moral standard in question.

If, on the other hand, there were a consensus on a particular measure, it would have two ready routes to adoption. First, there would be no member to challenge the measure. Second, the measure could be adopted explicitly by the membership as part of any package that might be adopted.

\subsection{The screening problem and consistency}

In the preceding section, we maintained the assumption that the country acting to protect the morals of its citizenry had motives that were pure. Virtually every commentator cited, however, notes the potential for an overly broad morals clause to be used as justification for protection. This concern is described in the chapeau of Article XX, which warns against 'disguised restriction on international trade', thereby suggesting the possibility of nefarious motives. The implication is that there is likely to be a heterogeneity of interests within the importing country's population (some may be offended by a measure; some may not) and there may be a multiplicity of motives among the country's leaders.

\subsubsection{The consistency check of the Panel and $A B$}

This multiplicity of motives ended up playing a critical role in the EC-Seal Products decisions. Howse, Langille and Sykes argue that the EU should be able to address the AB's concerns with ease, on the grounds that the EU could have successfully defended its Seals Regime had its motives been pure. ${ }^{24}$ The EU ran into trouble with both the Panel and the $\mathrm{AB}$ when it allowed exceptions for the hunts of

21 This may overstate the ease of reaching agreement, but in an interesting and relevant way. Countries might oppose agreement because they would fear interpretations of a new rule with which they might disagree. This would be an instance of the dangers of anticipated expansive interpretation, as discussed below.

$22 \mathrm{Wu}$, 'Free Trade and the Protection of Public Morals', supra note 17, p. 241.

23 Note, for example, common US disdain for proceedings of the UN General Assembly, as well as staunch US defense of its ability to block measure at the IMF.

24 Rob Howse, Joanna Langille, and Katie Sykes (2014), 'Sealing the Deal: The WTO’s Appellate Body Report in EC-Seal Products', ASIL Insights, 18(12): 4 June 2014, http://www.asil.org/insights/volume/18/ issue/12/sealing-deal-wto's-appellate-body-report-ec-seal-products. 
Indigenous Communities (IC), Marine Resource Management (MRM) and Transportation (importation of seals or seal products for re-export). The opining jurists seemed to question the sincerity of EU motives. If it is morally offensive to consume the products of a seal hunt, how can that moral offense disappear if the hunt is conducted by an IC member? ${ }^{25}$ Given the potential breadth of a 'moral concerns' exception described above, the sincerity of moral concerns understandably played a significant role. ${ }^{26}$

Howse, Langille and Sykes argue that this requirement for pure motives is unrealistic in a world with a range of competing interests:

A requirement of consistency would be unworkable in the real world of policymaking, where different considerations and priorities have to be balanced against one another, and the ideal of treating like moral challenges alike can never be perfectly achieved. The proposed approach would also have dramatically expanded the WTO's powers of legislative review, contrary to the WTO's institutional mandate.

The difficulty with their proposed deference to national political outcomes is that it would render it virtually impossible to question the sincerity of a moral concerns claim. Other than an explicit public survey in which there was a resounding 'we don't care!' response on the subject in question, almost any inference from the nature of the regime could be deflected with the argument that it was a concession to necessary political compromise. ${ }^{27}$ This only works if we grant the erectors of trade barriers free rein by assuming that motives are pure.

\subsubsection{Troublesome motives and separating equilibria}

Let us postulate, for the moment, that there are at least two 'types' that might back a regime restricting seals imports: those with permissible motives (e.g. moral concerns) and those with impermissible motives (e.g. protectionist concerns). One obviously cannot distinguish the two types just by asking (any self-respecting protectionist would claim pure motives).

This challenge is a familiar one for economics. ${ }^{28}$ There are plenty of examples when one wishes to distinguish two types on the basis of unobserved

25 The decisions spend ample time establishing that there is no real expectation that IC or MRM seal hunts would be more humane.

26 It is interesting to note that the EU public apparently has difficulty striking a balance between the different moral imperatives of protecting seals and supporting indigenous communities. The indigenous community in Greenland - the most likely intended beneficiary of EU Seals Regime exceptions - saw a decline in demand after the adoption of the regime. Even though their products were allowed in, consumers shunned them. See http://arcticjournal.com/politics/494/eu-ban-blamed-rapid-decline-greenland-sealing. This also raises questions that have been neglected in the main text about whether trade action is truly necessary if there is broad moral concern.

27 This somewhat exaggerates the case. Panels have subjected the stated purposes of defendants to scrutiny.

28 For a survey, see John G. Riley (2001), 'Silver Signals: Twenty-Five Years of Screening and Signaling', Journal of Economic Literature, 39(2): 432-478. 
characteristics. For example, employers might want to distinguish between dedicated and flighty workers. Insurance companies might want to distinguish between careful and careless drivers. There is even, arguably, a GATT example the attempt to distinguish between a pair of countries with a sincere desire to pursue closer economic relations and pairings that just want to undermine MFN.

In each case, the solution is to adopt requirements that lead to a separating equilibrium, in which one group will be willing to meet the requirements and another group will not. For employers, they can require a college degree. For insurers, they may require a high deductible. In the GATT context, Article XXIV requires that FTAs cover substantially all trade and be concluded in a reasonable period of time.

The important point to note is that separating equilibria are not tailored to maximize welfare; they are tailored to play off preferences in such a way that different types reveal themselves. In fact, if an approach is acceptable to both types, then it is a pooling equilibrium, not a separating equilibrium.

In the EC-Seal Products case, one interpretation of the Panel's qualms about multiple motives is that the panel was trying to establish a high threshold for the necessary intensity of moral concern. By disallowing balanced political compromises, the Panel meant to discern whether the EC's demonstrated preferences were intense or casual.

\subsection{Incomplete contracts and renegotiation}

A final economic perspective concerns the systemic effects of the EC-Seal Products decision. The scholarship and commentary on Article XX(a), along with the key decisions of US-Gambling and EC-Seal Products reveal two important characteristics:

1. Ample ex ante uncertainty about the range of permissible actions under the clause (some of which persists in the wake of the Panel and $\mathrm{AB}$ decisions).

2. A very broad range of potential economic outcomes (illustrated by the difficulty in establishing limits in Section 2.1).

For the purposes of this section, let us distill the trade world down to two countries: Complainant (a Canadian/Norwegian amalgam) and Respondent (representing the EC). We imagine that Complainant and Respondent initially sign a trade agreement in which each offers market access concessions to the other. The deal is struck when each country assesses that the combination of concessions is preferable to the status quo ante. If the two countries were able to foresee all potential contingencies and were equipped with inexhaustible lawyers, they could create a complete contract that would clearly cover any event to come. Far more likely, however, is that a lack of foresight or legal resources would require an incomplete contract. Such a contract would use vague phrases such as 'moral concerns' rather than providing a precise definition of what exactly this covers. At the decision stage, when each country is trying to decide whether to sign the 
contract (trade agreement), they must base their assessments on their interpretations and expectations about what such vague phrases will mean in practice. ${ }^{29}$

In this setting, we will treat the EC-Seal Products case as one that establishes a clear path for the Respondent to restrict Complainant's access in the seal market. We will further assume that the restriction came as a surprise-Article XX(a) emerged as more potent than Complainant had expected.

Under these assumptions, what is the implication of the decision for the state of trade relations between the two countries, present and future? We conclude our analysis with a number of scenarios:

1. If we interpret EC-Seal Products as an unexpected restriction on Complainant's market access, we can first consider the possibility that the change is symmetric. If Complainant can identify moral concerns within its populace that justify equivalent restrictions on Respondent's market access, we will end up in a setting very much like a dispute with retaliation imposed. The balance of concessions will be preserved, but market access will be less generous.

2. If Complainant cannot plausibly identify equivalent moral concerns, then the balance of concessions will be upset. Now, from a political perspective, Respondent will see the reinterpreted agreement as more appealing, while Complainant will see it as less appealing. Presumably, at some point, an imbalance could cause Complainant to consider whether the agreement was worthwhile.

3. The situation gets more interesting if we think of the Complainant-Respondent agreement as evolving through repeated negotiations, rather than as a singleshot accord. In this case, we can draw on the lessons of Kydland and Prescott's seminal work on time-inconsistency. ${ }^{30}$ If Complainant now expects to have Respondent limit promised market access in future periods, Complainant will limit the concessions it makes at the time of agreement. Typically, the result is that the potential for negative surprises (discretion) can result in an inferior equilibrium to a precommitment to a set of rules (in this case corresponding to the expectations of a narrower interpretation of Article $\mathrm{XX}(\mathrm{a}))$.

4. A more difficult situation to analyze occurs if we consider repeated interactions in which Complainant can use the broader interpretation of Article XX(a) to rebalance concessions with Respondent. In this case, we can think of the broadening

29 There is a nascent literature on incomplete contracts and renegotiation in trade agreements. See, in particular, Giovanni Maggi, and Robert W. Staiger (forthcoming) 'Optimal Design of Trade Agreements in the Presence of Renegotiation', American Economic Journal: Microeconomics. While this is one sign of the importance of the issue, the literature is still at a stage at which it is difficult to apply directly to cases such as the one at hand.

30 Finn E. Kydland and Edward C. Prescott (1977), 'Rules rather than Discretion: The Inconsistency of Optimal Plans', The Journal of Political Economy, 85(3): 473-491. 
of interpretation as increasing the variability of outcomes (risk) associated with any particular clause of an agreement. As with investment risk, this increased variability can result in outcomes that are considered significantly more positive or significantly more negative. A question for future political economy research is how the higher variability would affect the willingness of Complainant and Respondent to strike deals.

\section{Legal analysis}

In this section, we discuss the TBT issues in both the Panel and Appellate Body reports. As we explained in the Introduction, the EU seal products regime bans the import and marketing of seal products. The ban covers both pure seal products (such as skins or pure seal oil) and products containing seal (such as seal fur coats, or food supplements combining seal oil and other ingredients). There are three exceptions to the ban, the IC (indigenous communities) exception, the MRM (marine resources management) exception, and the Travelers' exception. The Travelers' exception was not challenged. As between the IC exception and the MRM exception, the IC exception is much more important: it gets much more attention, and all the important legal issues are raised in connection with it. So we shall discuss only the IC exception, often writing, for convenience, as if it were the only one. It is worth noting here, for those who worry that tribunals will be too generous in allowing moral purposes, that while the Panel found the IC exception had a legitimate purpose that was not evenhandedly applied, it rejected the MRM exception's purpose outright (and the EU did not bother to appeal this rejection).

The seal products regime consisted of a basic regulation, adopted by the European Parliament and Council on 16 September 2009,31 and implementing regulations for the exceptions, adopted by the Commission on 10 August $2010 .{ }^{32}$ By general agreement, the basic regulation and implementing regulations were treated as a single measure. Limiting ourselves to the TBT challenges, Canada challenged the measure under TBT 2.1, 2.2, 5.1.2, and 5.2.1. Norway challenged the measure under TBT 2.2, 5.1.2, and 5.2.1. The Panel found that the measure was a technical regulation, and that it violated TBT 2.1 and 5.1.2, first sentence. It found no violation of TBT 2.2, nor of 5.1.2, second sentence, nor of 5.2.1. The Appellate Body's only finding under the TBT was that the measure was not shown to be a technical regulation.

31 Regulation (EC) No 1007/2009 of the European Parliament and of the Council of 16 September 2009, Official Journal of the European Union, L Series, No. 286 (31 October 2009).

32 Commission Regulation (EU) No 737/2010 of 10 August 2010, Official Journal of the European Union, L Series, No. 216 (17 August 2010). 


\subsection{Whether the EU seal products regime is a 'technical regulation'}

The Appellate Body in EC - Measures Affecting Asbestos and Asbestos-Containing Products $^{33}$ set out three requirements for a measure to be a technical regulation, and hence subject to the provisions of TBT Article 2. The measure must apply to identifiable products; it must, in the words of TBT Annex 1.1 'lay down product characteristics or their related processes and production methods, including the applicable administrative provisions' (or else it must be about labeling and identification); and compliance with the measure must be mandatory. There was no controversy in EC-Seal Products about whether the measure applied to identifiable products, nor about whether it was mandatory. So we shall limit our attention to the requirement that the measure 'lay down product characteristics or their related processes and production methods, including the applicable administrative provisions' (or be about labeling), which we shall frequently refer to just as the requirement that it 'lay down product characteristics', remembering that that implicitly includes references to 'their related PPM's', 'applicable administrative provisions', and labeling and identification.

\subsubsection{The Panel's analysis}

The Panel finds that the EU seal products regime does 'lay down [a] product characteristic', and hence is a technical regulation. Their discussion is brief, and not a model of organizational clarity. The Panel begins its analysis by rehearsing two points from EC-Asbestos. First, they say:

The Appellate Body defined the term 'characteristics' in EC-Asbestos as 'any objectively definable "features", "qualities", "attributes", or other "distinguishing mark" of a product'. Such 'characteristics' include not only features and qualities that are intrinsic to the product itself, but also related characteristics, 'such as the means of identification, the presentation and the appearance of a product'. ${ }^{34}$

Then they continue immediately with:

In EC-Asbestos, the Appellate Body found that the prohibition on asbestos fibres as such did not, in itself, lay down any 'characteristics' because it simply banned asbestos fibres in their natural state. The prohibition on asbestos-containing products, however, was found to lay down a product characteristic in the negative form by requiring that all products must not contain asbestos. ${ }^{35}$

After summarizing very briefly the EU regulations, the Panel says that, in light of EC-Asbestos, the prohibition on seal-containing products lays down a product characteristic (namely, not containing seal). ${ }^{36}$ They say in a footnote that their

33 WT/DS135/AB/R (adopted 5 April 2001).

34 EC-Seal Products (Panel), para. 7.103, quoting EC-Asbestos, para. 67.

35 EC-Seal Products (Panel), para. 7.104, quoting EC-Asbestos, para. 71.

36 EC-Seal Products, para. 7.106. 
conclusion 'is not affected by the fact that the prohibition of seals 'in their natural state' might not, in itself, prescribe or impose any "characteristics". 37 But they never say unambiguously whether they see the EU measure a having a part that does not lay down a product characteristic, namely the ban on pure seal products (such as seal skins and pure seal oil). Instead, they jump to a discussion of 'applicable administrative provisions', namely the administrative provisions for enforcing the exceptions. They implicitly recognize that the relevant administrative provisions must be about product characteristics (or their related PPM's), 38 and by this route they back into a discussion of whether the exceptions lay down product characteristics. They decide that the exceptions do lay down product characteristics; and, on that basis, they decide that the measure as a whole is a technical regulation.

The Panel finds that the exceptions lay down product characteristics because they specify 'objectively definable features', ${ }^{39}$ a phrase they had quoted previously from the EC-Asbestos Appellate Body. But what the Appellate Body said in full (and the Panel had quoted) was that 'characteristics' included 'objectively definable "features", "qualities", “attributes", or other "distinguishing mark" of a product'. The full list here suggests a concern with intrinsic or near-intrinsic properties. This impression is greatly strengthened by the next sentence of the EC-Asbestos report, which the Panel did not quote. This sentence says that, 'Such "characteristics" might relate, inter alia, to a product's composition, size, shape, colour, texture, hardness, tensile strength, flammability, conductivity, density, or viscosity'. ${ }^{40}$ This is a list of intrinsic, or near-intrinsic, properties of the product and not, incidentally, properties related to the product's usefulness for particular purposes. All of them are a far cry from the 'feature' the Panel finds is a product characteristic, namely 'having been killed by an Inuit'. To be sure, the ECAsbestos Appellate Body also said, as the Panel quoted above, that 'product characteristics' are not limited to intrinsic features of the product itself, but include 'related "characteristics", such as the means of identification, the presentation and the appearance of a product'. But this reference to labeling and means of identification does not seem like an invitation to regard all non-intrinsic properties of a product as 'product characteristics'.

In the Panel's defense, we have got to a somewhat surprising place in TBT jurisprudence. Are the regulations in US-Tuna II (Mexico) ${ }^{41}$ and US-COOL, ${ }^{42}$ which are about labeling, really so different in substance from the EU seal regime? Like the

37 EC-Seal Products, n.153 to para. 7.106.

38 This is confirmed by the EC-Seal Products Appellate Body, in para. 5.13.

39 EC-Seal Products, para. 7.110.

40 EC-Asbestos, para. 67.

41 US - Measures Concerning the Importation, Marketing and Sale of Tuna and Tuna Products, WT/ DS381/AB/R (adopted 13 June 2012).

42 US - Certain Country of Origin Labeling (COOL) Requirements, WT/DS384 \& 386/AB/R (adopted 23 July 2012). 
EU seal regime, the regulations in US-Tuna II (Mexico) and US-COOL concern themselves with the history of the product, rather than with features or qualities we would think of as intrinsic to the products themselves. And yet both sets of regulations were uncontroversially regarded as 'laying down product characteristics', just because they involved labeling. What is the magic of labeling, that makes any regulation about labeling a technical regulation? The Appellate Body could well have read the references to 'terminology, symbols, packaging, marking or labelling requirements' in TBT Annex 1.1 as being about 'technical' aspects of labeling - for example, definitions of terms such as 'net weight' and 'dry weight', or a requirement that various product specifications be stated in particular units, or requirements on language or font size for the presentation of certain content, and so on. But after US-Tuna II (Mexico) and US-COOL, it seems that any regulation on labeling is going to qualify as a technical regulation. I am not sure this is the best reading of Annex 1.1, but, even so, there is a kind of sense to be made of it. We can suggest with some plausibility that aspects of labeling and packaging are 'product characteristics' that are intrinsic to the product as it is presented to the purchaser. When I walk into a grocery store, or a hardware store, I am not confronted with bare tuna-fish, or piles of bolts, or whatever. I am confronted with labeled cans of tuna-fish; or with packages of bolts; or even if it's a barrel of bolts that I can scoop some out of, there will normally be a sign to identify what type and size they are. So, even if the packaging and labeling are not features intrinsic to tuna-fish in the abstract, they are features intrinsic to the product that I buy.

Whatever our view about labeling regulations as technical regulations, the EU seal regime was not about labeling, and 'having been killed by an Inuit' is not plausibly regarded as a 'product characteristic' in the sense of TBT Annex 1.1.43 Another argument against the Panel's analysis is that it makes the reference in the first sentence of TBT Annex 1.1 to 'product characteristics or their related processes and production methods' pleonastic. On the Panel's approach, according to which 'having been killed by an Inuit' is a product characteristic, it would seem that any PPM lays down a product characteristic; so once we have mentioned product characteristics in the definition of technical regulations, there is no need to say anything further about PPM's. Nor can we understand this as a case of precautionary redundancy. If that had been the drafters' intention, they presumably would have said 'product characteristics, including their related processes and production methods' instead of 'product characteristics or their related processes and production methods' (emphasis added). It is particularly ironic that the Panel's

43 The suggestion that PPM's are not 'product characteristics' within the meaning of TBT Annex 1.1 is perfectly consistent with the argument Rob Howse and I have made that PPM's are relevant to 'likeness' in GATT I:1 and III:4. The two issues involve different terms, in different contexts. See Robert Howse and Donald Regan (2000), 'The Product/Process Distinction-An Illusory Basis for Disciplining "Unilateralism" in Trade Policy', European Journal of International Law, 11(2): 249-289. 
approach would turn all PPM's into product characteristics, in view of the fact that the Panel later claims to have been able to avoid deciding any issue about PPM's. ${ }^{44}$

\subsubsection{The Appellate Body's analysis}

The Appellate Body disposes very brusquely of the suggestion that 'having been killed by an Inuit' is a product characteristic. They write: 'We see no basis in the text of Annex 1.1, or in prior Appellate Body reports, to suggest that the identity of the hunter, the type of hunt, or the purpose of the hunt could be viewed as product characteristics. ${ }^{45}$ (They also remark in a footnote that TBT 2.9 presupposes that technical regulations have 'technical content', which they suggest does not include the identity of the hunter or the purpose of the hunt.) ${ }^{46}$ But, of course, deciding that 'having been killed by an Inuit' is not a product characteristic does not end the Appellate Body's consideration of the case. They appear to endorse the Panel's suggestion, based on EC-Asbestos, that a simple ban on pure seal products would not lay down a product characteristic, while a simple ban on seal-containing products would. So how do they decide that the actual regime, which bans both pure seal products and seal-containing products, is not a technical regulation? ${ }^{47}$ The Appellate Body emphasizes both that the tribunal must consider the measure 'as a whole' and that the tribunal must try to identify the 'integral and essential' aspects of the measure. ${ }^{48}$ These ideas, seemingly in some tension, suggest two distinct approaches, and it is not entirely clear which the Appellate Body most relies on.

The first approach involves 'nose-counting'. Insofar as it relies on this approach, the Appellate Body first identifies three salient aspects of the regime: (1) it bans pure seal products; (2) it bans seal-containing products; and (3) it has an exception for products (pure seal or seal-containing) that result from Inuit hunts. The Appellate Body then observes that with regard to the question whether the regime is a technical regulation, (1) the regime's banning pure seal products counts against its being a technical regulation; (2) the regime's banning seal-containing products counts in favor of its being a technical regulation; and (3) the fact that the exception does not lay down a product characteristic counts against the regime's being a technical regulation. So the score is two-to-one against, and the regime is not a technical regulation. ${ }^{49}$

44 EC-Seal Products (Panel), para. 7.112.

45 EC-Seal Products (Appellate Body), para. 5.45.

46 Ibid., n. 942 to para. 5.45.

47 Technically, all they do is overturn the Panel's finding that the regime is a technical regulation. They decline to decide whether the regime might be a technical regulation because it lays down a 'related process [or] production method', citing the lack of discussion of this issue by the parties or the Panel. But for convenience I shall speak hereafter as if they find that the measure is not a technical regulation.

48 Ibid., para. 5.19.

49 Ibid., paras. 5.30, 5.58 first part. 
The Appellate Body's second approach involves identifying the most 'integral and essential aspect' of the measure, which in the Appellate Body's view is the exception. ${ }^{50}$ Focusing on this most 'integral and essential aspect', the Appellate Body concludes that the measure is not a technical regulation, because the exception does not lay down a product characteristic. ${ }^{51}$ But in general, trying to identify the most 'integral and essential aspect' of a complicated regulatory scheme is a senseless task. Illustrating that point, the Appellate Body's identification of the exception as the most 'integral and essential' aspect in this case seems bizarre. The Appellate Body says the 'prohibition on the products containing seal [i.e., the ban] seems to be derivative of the ... permissive component of the measure [the exceptions]'. ${ }^{52}$ But how can the ban be 'derivative' of the exceptions, when its purpose, which is preventing moral outrage at seal suffering, is completely distinct from the purpose of the exceptions, which is allowing the preservation of Inuit culture, and so on? Surely it is clear that the EU first conceived of the ban, and only then realized that it wanted the IC exception (and the others).

There are cases where it does seem plausible to think of the ban as derivative. For example, the stadium owner who excludes people from the baseball game unless they buy a ticket. There is no independent purpose for the ban on entry; the owner is not trying to minimize the number of people in the stadium. It's just that excluding people who don't have a ticket is the only way to get people to buy tickets. In this example, there is only one purpose, getting ticket revenue; and the function of the ban is simply to provide an incentive for people to buy tickets (that is, to bring themselves within the exception). So the ban does indeed seem derivative. Conversely, there are cases where the exception may seem derivative, for example, the final US shrimp-turtle regulation, which (simplified) says that no shrimp harvested without US-style turtle-excluder devices [TED's] can enter the US market, except shrimp from places where there are no turtles. Here the only purpose is protecting turtles, and the ban is what achieves that purpose. The exception is for cases where the purpose simply is not implicated. But the EC-Seal Products case is not like either the ball-park case or the shrimp-turtle case. In EC-Seal Products, there are two distinct purposes, which sometimes conflict; people cannot act to bring themselves within the exception; and the purpose of the ban is fully implicated even in the cases where the exception is made. In truth, EC-Seal Products represents the only sort of case where it is entirely natural to talk about a 'ban' and an 'exception'. There is something forced about describing either of the other cases that way. But enough. I hope we have said enough to establish the oddity of saying the ban is 'derivative' in EC-Seal 
Products, and to suggest the fruitlessness of asking, in complex cases, what aspect of the regulation is most 'integral and essential'.53

In the end, neither the nose-counting-over-all-aspects approach, nor the approach of deciding by reference to the most 'integral and essential' aspect, seems to make much sense. Consider what happens if we try to apply these approaches to an even simpler case. Imagine that the EU seal regime consisted only of the ban, on both pure seal products and seal-containing products, with no exceptions. Would this be a technical regulation or not? On the nose-counting approach as applied by the Appellate Body, the score over distinct aspects is a oneto-one tie. We might break the tie by saying it is the complaining Member's burden to show the measure is a technical regulation; so in case of a tie, the regulation is not a technical regulation. But this 'burden of proof' approach does not seem apposite when the issue is the purely legal issue of whether a measure is a technical regulation, where no relevant facts about how the measure operates are in dispute. If instead we adopt the 'most integral and essential aspect' approach, how do we decide whether it is the ban on pure seal products or the ban on seal-containing products that is dominant? The only apparent test would be the quantity (or value, or some such) of commerce in each category; but then the measure would be a technical regulation or not, depending on whether the commerce in seal-containing products was just more or just less than half the total.

There is another possible approach, overlooked by both the Panel and the Appellate Body, that might seem more sensible. We could distinguish between the measure as applied to pure seal products, and the measure as applied to sealcontaining products. If there are doubts about the textual basis for such an 'as applied to ...' distinction, we could follow the lead of the Panel in EC-Biotech Products ('GMOs'), in their discussion of a ban justified by multiple purposes. ${ }^{54}$ We could say that the EC seal products regime actually creates two measures, one applying to pure seal products, and the other applying to seal-containing products. But this approach is problematic as well. There is no apparent reason why a measure about products containing seal (which would be a technical regulation on the EC-Asbestos approach) should be subject to the distinctive disciplines of TBT 2.2 and 2.4, while a measure about pure seal products is not.

The true upshot of all this may be that we need a deeper rethinking of our approach to the TBT. Perhaps we should pay more attention to the idea that the TBT is supposed to be about technical regulations and standards. As we noted above, when the EC-Asbestos Appellate Body gave examples of 'product characteristics', it was a very technical-sounding list ('composition, size, shape, colour, texture, hardness, tensile strength, flammability, conductivity, density, or

53 The Appellate Body's confusion could be made more understandable by discussing the peculiar drafting of both the EU's basic regulation and the implementing regulations. But space limitations forbid.

54 EC - Measures Affecting the Approval and Marketing of Biotech Products, WT/DS291 \& $292 \&$ 293/R (adopted 21 November 2006), paras. 7.162-7.170. 
viscosity') of intrinsic, or near-intrinsic, properties related to the product's usefulness and appropriateness for particular purposes. This case report is not the place for a full discussion of the possibilities for such a rethinking of the coverage of the TBT Agreement. But it does not seem too late both to reconsider the EC-Asbestos distinction between regulation of asbestos in its natural state and of asbestos-containing products (which was arguably dictum in that case, since there was apparently no market in natural fibers), and to look for a more 'technical' approach to 'product characteristics'. In light of US-COOL and US-Tuna II (Mexico), it may be too late to limit the relevant labeling requirements to technical aspects of labeling. But the only non-labeling cases before EC-Seal Products are ECAsbestos and US - Clove Cigarettes, ${ }^{55}$ both of which seem to involve genuinely technical requirements (no asbestos, no clove flavoring). And in EC-Seal Products, despite the unsatisfactoriness of some of the Appellate Body's analysis, they do reject the idea that 'having been killed by an Inuit' is a product characteristic. Their overall conclusion that the regime has not been shown to be a technical regulation may reflect the intuition that it just isn't the sort of regulation the TBT was supposed to be about.

\subsection{Whether the EU seal products regime violates TBT 2.1}

TBT 2.1 is about discrimination, and the only source of discrimination in EC-Seal Products is the IC exception. (Remember we are ignoring the other exceptions.) The ban itself is non-discriminatory: it does not discriminate among seal products, and Canada did not argue that it discriminated against Canadian seal products in favor of European fox or mink products. So, the problem under 2.1 is the legality of the IC exception. The legality of the ban is an issue for 2.2.

There is no major innovation in the Panel's 2.1 analysis, which by and large follows the approach laid out in US-Clove Cigarettes. But the Panel does make the structure of the analysis clearer than the Appellate Body ever has, in particular, by clarifying whether 'evenhandedness' has a distinct role in the analysis, or whether it is just another conclusory term like 'discrimination'. The Panel lays out a blueprint for 2.1 analysis (both the national treatment and most-favored nation aspects) that precisely tracks the Appellate Body's current scheme for analysis under GATT III:4. ${ }^{56}$ In the Panel's analysis, the question whether the measure is

55 US - Measures Affecting the Production and Sale of Clove Cigarettes, WT/DS406/AB/R (adopted 24 April 2012).

56 I say 'the Appellate Body's current scheme', because the Appellate Body's GATT III jurisprudence has been notably unstable. The Appellate Body was generally understood to say in Japan-Taxes on Alcoholic Beverages, WTO/DS8 \& 10 \& 11/AB/R (adopted 1 November 1996), sec. H.2(c), that regulatory purpose was irrelevant to the existence of violations under GATT III:2. But in Chile-Taxes on Alcoholic Beverages, WT/DS87 \& 110/AB/R (adopted 12 January 2000), paras. 62, 71, the Appellate Body told us that regulatory purpose was absolutely relevant under III:2, second sentence, and that Japan-Alcohol had in fact meant precisely that. In EC-Asbestos, para. 99, interpreting GATT III:4, the Appellate Body excluded regulatory purpose from the 'likeness' inquiry, saying that 'likeness' was a 
'evenhanded' under TBT 2.1 corresponds to the question whether it satisfies the chapeau of GATT XX.

Let us take it step-by-step. The first question in the Panel's 2.1 analysis is whether the measure involves 'like products'. This is precisely the same question under TBT 2.1 as it is under GATT III:4, since US-Clove Cigarettes simply imported into TBT 2.1 the current GATT III:4 definition of 'likeness' in terms of 'competitive relationship'. ${ }^{57}$ The next question the Panel asks is whether there is 'less favorable treatment' for some foreign products. This question is subdivided into (a) whether there is disparate impact on competitive conditions, and (b) whether, if so, the disparate impact 'stems exclusively from legitimate regulatory distinctions'. Question (a), about disparate impact, corresponds to the question whether there is 'less favorable treatment' in the Appellate Body's current approach to GATT III:4, since they seem to regard 'less favorable treatment' as involving just disparate impact. $^{58}$ The Panel's question (b), about whether the disparate impact stems from legitimate distinctions, is further subdivided into (i) whether there is a 'legitimate regulatory purpose', and (ii) whether the regulation pursues that purpose 'evenhandedly'. Question (i), about legitimate regulatory purpose, corresponds to the question whether the measure comes within one of the specific sub-paragraphs of GATT XX; and question (ii), about 'evenhandedness', corresponds to the question whether the measure satisfies the chapeau of GATT XX. ${ }^{59}$ (Despite

matter of competitive relationship; but they then presented us with a mystery box in their enigmatic paragraph 100 on 'less favorable treatment'. In Dominican Republic-Measures Affecting the Importation and Internal Sale of Cigarettes, WT/DS302/AB/R (adopted 19 May 2005), para. 96, the Appellate Body said explicitly that there was not 'less favorable treatment' if the disparate impact was explained by factors unrelated to the foreign origin of the products. Then in US-Clove Cigarettes, n. 372 to para. 179, the Appellate Body simply denies that Dominican Republic-Cigarettes was concerned with whether the disparate impact was explained by foreign origin. The US-Clove Cigarettes Appellate Body dismisses one sentence where Dominican Republic-Cigarettes said that explicitly, and they ignore a later sentence in the same paragraph that repeated the point. Instead, they quote a sentence from in between those two sentences about foreign origin. It is true that the sentence the US-Clove Cigarettes Appellate Body quotes did not mention foreign origin; the reason is that it was describing what the other explanation, unrelated to foreign origin, was in the actual case. In sum, history gives us little reason to expect that the Appellate Body's GATT III:4 jurisprudence five years hence will be what it is now. For the full story, and my preferred approach, see Donald Regan (2012), 'Regulatory Purpose in GATT Article III, TBT Article 2.1, the Subsidies Agreement, and Elsewhere: Hic et Ubique', in Denise Prevost and Geert Van Calster (eds.), Research Handbook on Environment, Health, and the WTO, Edward Elgar, pp. 41-78, at 42-61.

57 I have suggested elsewhere that importing the GATT III: 4 criterion of 'likeness' into TBT 2.1 was a mistake. Regan, 'Regulatory Purpose', supra note 53, at 61-68.

58 See, e.g., EC-Seal Products, Appellate Body, para. 5.125, and the discussion of US-Clove Cigarettes, supra note 53.

59 Some sub-paragraphs of GATT XX, those stated in terms of 'necessity', require a least-restrictivealternative analysis, while others do not. But even when the sub-paragraph does not require least-restrictive-alternative analysis, the Appellate Body has read such a requirement into the chapeau, as in the decision in US-Import Probibition of Certain Shrimp and Shrimp Products, WT/DS58/AB/R (adopted 6 November 1998), that US-style TED's were not necessary in Malaysian shrimping grounds. So it seems that, one way or another, least-restrictive-alternative analysis is always required under GATT XX. It is not entirely clear whether the EC-Seal Products Panel would do this analysis under question (b)(i) or 
this structural isomorphism, we shall see below that the range of possible justifying purposes may be broader under TBT 2.1 than under GATT XX; and the burden of proof may not be allocated the same way.)

In EC-Seal Products, the issue of whether all seal products were 'like' was not controverted. The issue about disparate impact on competitive conditions was controverted, but the Panel decided without difficulty that there was disparate impact, and this need not detain us. So we are left with the questions whether there was a legitimate regulatory purpose, and whether that purpose was implemented evenhandedly.

\subsubsection{Legitimate regulatory purpose: the indigenous culture purpose (and the phantasmal 'Brazil-Tyres rule')}

The EU says the purpose of the IC exception is to allow the preservation of Inuit culture. (We shall allow the Inuit, the only indigenous communities involve in the present case, to stand in for all indigenous communities.) It is striking that the EU apparently does not characterize its concern for Inuit culture as a matter of public morals, since they do characterize their concern for seal welfare that way (as we discuss in Section 3.3). Nor does the Panel ever characterize the concern for Inuit culture as a matter of public morals. ${ }^{60}$ In fact, the Panel treats the concern for Inuit culture as a legitimate purpose, without attempting to bring it under any bit of WTO text at all. The Panel does point to international conventions and resolutions that assert the rights of indigenous peoples to maintain their cultures. But it carefully says that it uses these international documents only as 'factual evidence' that 'demonstrate[s] the recognized interests of Inuit and indigenous peoples in preserving their traditions and cultures'. ${ }^{61}$ Remarkably, Canada does not seem to object (or no more than half-heartedly) to the idea that a purpose to allow preservation of Inuit culture can be a legitimate purpose in principle under the TBT. That may be because of Canada's lack of success in arguing against the consumer-information purpose in US-COOL. Or it may be because Canada has a different sort of objection to the EU's relying on the Inuit culture purpose in this context. (We will return to Canada's objection in a moment.)

The Panel does not offer any general discussion of what is a 'legitimate purpose' under the TBT. But the most natural reading of their approach suggests that they regard any sincerely held purpose as legitimate, provided it is not protectionism

(b)(ii) above, but there is no reason to doubt that they would regard failure to use a less restrictive alternative as relevant. (This does not make TBT 2.2 redundant, since 2.2 applies even when there is no disparate impact.)

60 One could argue that it does so implicitly when it writes, '[W]e did not consider that the evidence before us supports the European Union's position that the EU public attributes a higher moral value to the protection of Inuit interests as compared to seal welfare' (EC-Seal Products (Panel), para. 7.299. But this is in any case a negative judgment on the idea that the particular resolution of the seals/Inuit conflict represents a formed view of the EU public.

61 Ibid., para. 7.295 . 
(in the national treatment context), or does not involve favoritism for traders of one country over another (in the most-favored nation context). On this view, we are not looking for a positive list of legitimate purposes; rather, we have a much shorter list of purposes that are not legitimate. Both in principle and in practice, these are very different approaches. And focusing on identifying and restraining illegitimate purposes is more consistent with the general spirit of the WTO as a negative integration agreement.

Notice that focusing on illegitimate purposes under the TBT may mean that a wider range of regulatory purposes are acceptable under the TBT than under GATT Article XX. One has to stretch, for example, to bring the Inuit culture purpose within GATT XX. Is Inuit culture a 'national treasure of artistic, historic or archaeological value' under $\mathrm{XX}(\mathrm{f})$ ? Can we argue under $\mathrm{XX}(\mathrm{b})$ that destruction of indigenous cultures tends to have negative effects on public health? Or must we rely on the kitchen-sink interpretation of the 'public morals' exception of $\mathrm{XX}(\mathrm{a})$ ? As long as the Appellate Body is committed to not considering regulatory purpose under GATT III:4 or GATT I:1, there will be pressure to expand Article $\mathrm{XX}$ to cover all purposes that are not illegitimate. ${ }^{62}$ And if we do not expand Article XX, the range of permissible purposes under the GATT will be narrower than the range under the TBT. ${ }^{63}$

Now back to Canada's objection to relying on the Inuit culture purpose to justify the IC exception. Canada relies on Brazil-Tyres ${ }^{64}$ for the proposition that if an exception to a prima facie justified ban has a disparate impact, then that exception can only be justified by reference to the same purpose that justifies the ban itself. Confronted with this argument, the EC-Seal Products Panel finds that the IC exception is not justified by the public morals purpose that justifies the ban, since the evidence does not establish that Inuit hunts are more humane than commercial hunts (indeed, the evidence may suggest that they are less humane). ${ }^{65}$ But even though the Panel seems to accept Canada's assertion of the existence of the 'Brazil-Tyres rule' against multiple purposes, they decline to apply the rule in this case; and they find that the EU can justify the IC exception by the separate purpose of preserving Inuit culture. The Panel's sketchy argument about why this case is different from Brazil-Tyres seems entirely conclusory. ${ }^{66}$ Nonetheless,

62 Similarly, the Appellate Body's very generous interpretation in US-Measures Affecting the CrossBorder Supply of Gambling and Betting Services, WT/DS285/AB/R (adopted 7 April 2005) of 'public morals or public order' in GATS XIV(a) was necessitated by their mistaken finding of a XVI:2(a) violation. See Donald Regan (2007), 'A Gambling Paradox: Why an Origin-Neutral 'Zero-Quota' Is Not a Quota Under GATS Article XVI', Journal of World Trade, 41(6): 1297-1317, and other articles cited there.

63 The EC-Seal Products Appellate Body, paras. 5.126-5.129, is notably ambivalent about whether this is the case, and whether they care.

64 Brazil-Measures Affecting Imports of Retreaded Tyres, WT/DS332/AB/R (adopted 17 December 2007).

65 EC-Seal Products (Panel), para. 7.275.

66 See EC-Seal Products (Panel), paras. 7.296-7.298. 
the Panel is right to ignore the 'Brazil-Tyres rule'. The rule makes no sense; the only argument that is suggested for it in Brazil-Tyres is based on a misunderstanding of US-Shrimp; and there is a charitable reading available on which the Brazil-Tyres Appellate Body did not mean to lay down the rule at all.

As to why the putative Brazil-Tyres rule makes no sense, reasonable regulators often have multiple legitimate purposes, which point in different directions in particular cases. Here the EU wants to discourage inhumane seal hunting, and it also wants to allow preservation of the Inuit way of life. In the case of Inuit seal hunting, these purposes come into conflict. There is no reason at all to say that because it is the former purpose that explains the ban, that purpose must prevail in all cases of conflict. A fair-minded regulator could perfectly well conclude that when the purposes conflict, it is more important to allow the expression of Inuit culture than to protect seals. We may well think that as the regulatory regime responds to more and more purposes, the opportunities for covert protectionism, or for favoritism between trading partners, increase, so we should look for such covert purposeful discrimination with special care. But the danger of covert protectionism is not so great, nor so unmanageable, that it calls for a flat rule that the regulator must respond to only one purpose, a rule that would do enormous violence to sensible decision making. If both purposes appear to be genuine, as they do here, the regulator should be free to decide as it will about cases of conflict, unless there is persuasive evidence of misbehavior.

The only argument the Brazil-Tyres Appellate Body gave for their supposed suggestion that an exception must be justified by the same purpose as the underlying ban was an analogy to US-Shrimp. They wrote:

We note, for example, that one of the bases on which the Appellate Body relied in US-Shrimp for concluding that the operation of the measure at issue resulted in unjustifiable discrimination was that one particular aspect of the application of the measure (the measure implied that, in certain circumstances, shrimp caught abroad using methods identical to those employed in the United States would be excluded from the United States market) was 'difficult to reconcile with the declared objective of protecting and conserving sea turtles'. Accordingly, we have difficulty understanding how discrimination might be viewed as complying with the chapeau of Article XX when the alleged rationale for discriminating does not relate to the pursuit of or would go against the objective that was provisionally found to justify a measure under a paragraph of Article XX'. [Citations to US-Shrimp omitted.] ${ }^{67}$

But the situation in Brazil-Tyres was completely different from the situation in US-Shrimp. The United States in US-Shrimp did not claim to have multiple purposes (as Brazil did in Brazil-Tyres). The only justifying purpose the US offered for any aspect of the measure was the protection of turtles. So, of course, if some 
discriminatory feature of the measure was not justified by that purpose, it was not justified; but only because there was no other purpose on offer. In US-Shrimp, the Appellate Body did not reject any proffered purpose on the ground that it was different from the purpose of the ban. ${ }^{68}$

There is a way to make sense of Brazil-Tyres, which makes the analogy to USShrimp more plausible, and which suggests that the Appellate Body in Brazil-Tyres was not really relying on the 'Brazil-Tyres rule' at all. In Brazil-Tyres, the purpose of the import ban was protection of health, and the purpose that was offered to justify the exception for Mercosur countries was complying with a Mercosur tribunal's judgment. Arguably, this was not a legitimate purpose at all in the context of the case. For one thing, it is not clear that Brazil actually had an obligation under Mercosur, except by virtue of its own incompetence in not relying on Mercosur's Article $\mathrm{XX}(\mathrm{b})$ analogue in the Mercosur proceeding against it. (Incompetence, unless it was attempting to create a WTO justification for favoring its Mercosur partners.) Even if Brazil did have an obligation under Mercosur, a WTO Member cannot simply supersede its WTO obligation, at least not for WTO purposes, by pointing to some other conflicting treaty obligation. (In some circumstances, of course, GATT Article XXIV allows precisely this, but the Brazil-Tyres Appellate Body argued that Article XXIV did not save Brazil in this case. ${ }^{69}$ So Brazil's purpose of satisfying its Mercosur obligation was simply not a legitimate purpose at all, in this context; and that is why Brazil could not rely on it.

The Brazil-Tyres Appellate Body never says flatly that complying with the Mercosur judgment is not a legitimate purpose (perhaps because they were bemused by the fact that it obviously is legitimate in the abstract). But they do discuss all the reasons we have given for finding the purpose illegitimate in this context. Furthermore, whenever they explain specifically why Brazil cannot rely on the compliance purpose, they say things like the following: 'In our view, the ruling issued by the MERCOSUR arbitral tribunal is not an acceptable rationale for the discrimination, because it bears no relationship to the legitimate objective pursued by the Import Ban that falls within the purview of Article $\mathrm{XX}(\mathrm{b})^{\prime} \cdot{ }^{70}$ There is always a reference to Article XX, which suggests that the Appellate Body is troubled, not simply by the fact that the compliance purpose is different from the health purpose, but more specifically by the fact that the compliance purpose does not seem to fit under Article XX, as the health purpose does. If we

68 Note also that in US-Shrimp, there was no question of justifying an exception to the underlying ban; there was no exception. The US-Shrimp Appellate Body's objection to the feature of the measure they were discussing was that the ban itself was overbroad with respect to its purpose; the ban forbade more than the purpose could explain. In effect, the US-Shrimp Appellate Body was complaining about the failure to have an 'exception' that was required by the purpose of the ban.

69 Brazil-Tyres, n. 445 to para. 234.

70 Ibid., para. 228. 
read the Appellate Body as responding to the reasons for regarding the compliance purpose as illegitimate in the context, then Brazil-Tyres says nothing at all about how to deal with multiple legitimate purposes, in EC-Seal Products or any other case.

The EC-Seal Products Appellate Body discusses the 'Brazil-Tyres rule' briefly, without clearly relying on it. They write:

[T] he European Union has failed to demonstrate, in our view, how the discrimination resulting from the manner in which the EU Seal Regime treats IC hunts as compared to 'commercial' hunts can be reconciled with, or is related to, the policy objective of addressing EU public moral concerns regarding seal welfare. In this connection, we note that the European Union has not established, for example, why the need to protect the economic and social interests of the Inuit and other indigenous peoples necessarily implies that the European Union cannot do anything further to ensure that the welfare of seals is addressed in the context of IC hunts [which can also cause seal suffering]. ${ }^{71}$

The first sentence of this sounds like the 'Brazil-Tyres rule' pure and simple. That would be unfortunate. But the second sentence suggests something subtler: that we might allow the exception to be justified by a purpose different from, and even in conflict with, the purpose of the ban, provided that the exception is designed in such a way as to minimize the negative effect on the purpose of the ban from any specified degree of achievement of the purpose of the exception. That makes better sense. (Or at least, it would make better sense in a context where the ban itself required a justifying purpose, as it does under TBT 2.2 in the Panel's analysis, or as it did in Brazil-Tyres, which involved an import ban that violated GATT XI:1. But the EC-Seal Products Appellate Body is deciding the case under GATT I:1, so the ban itself, being non-discriminatory, actually required no formal justification. It seems odd to judge the exceptions in part by the purpose of the ban, which arguably need never have come to the tribunal's official notice.)

\subsubsection{Evenhandedness}

Having decided that the purpose of preserving Inuit culture was legitimate, the Panel faced one final question: whether the IC exception implemented this purpose evenhandedly. Note that the exception might fail to be evenhanded either (a) with regard to the distinction between the Greenland Inuit and Canadian commercial seal-hunters, or (b) with regard to the distinction between the Greenland Inuit and Canadian Inuit. The Panel considers a variety of evidence, some of which is relevant to both questions, and some of which is relevant only to the second question, without for the most part saying explicitly which question it is concerned with. This vagueness leaves it unclear just what violation the Panel finds, which means it is also unclear what violation must be corrected to bring 
the measure into compliance. We should not have to speculate about what the violation is. Tribunals should make it clear what aspects of a measure they are finding illegal.

On the whole, it seems likely that the Panel found the measure un-evenhanded only in the disparate treatment of the Greenland and Canadian Inuit, so we will focus on that. Deciding whether the measure is evenhanded involves a highly fact-based inquiry, and it is not our goal to say whether the Panel was right to find the measure was not evenhanded. But there are things to say about the legal structuring of the factual discussion, and on the proper interpretive approach to certain aspects of the evidence. The first requisite is to be as specific as we can about what 'evenhandedness' requires. The Panel sometimes writes as if the measure is un-evenhanded just because of its disparate impact. Thus: 'This [de facto exclusive access for Greenland Inuit] suggests in our view that the IC exception was not designed or applied in an even-handed manner so as to make the benefits of the exception available for all potential beneficiaries. ${ }^{72}$ But disparate impact cannot be enough. After all, the whole point of the general inquiry into 'legitimate regulatory justification' is to validate some measures with disparate impact. Also, if the Panel really thought disparate impact was all that mattered, its discussion of evenhandedness could have been drastically shorter.

If the issue is not simply disparate impact, it is tempting to suggest the issue must be discriminatory purpose. But this would be too quick. In US-Shrimp, for example, 'arbitrary discrimination' was found on the basis of procedural inadequacies in the United States' system for certifying other countries' turtle-protection regimes. And one element of 'unjustified discrimination' was the refusal to certify countries that did not require US-style turtle-excluder devices [TED's], even when TED's were not necessary for turtle-protection. Neither of these defects of the measure involved objectionable purpose. On the other hand, the EC-Seal Products Panel does not discuss any analogues of these defects in the EU seal products regime. So it appears that the issue about evenhandedness in EC-Seal Products must be about purpose.

Even if that is right, there is still an important distinction to be made. Some people argue that the EU regime cannot have had the purpose of favoring the Greenland Inuit, because they were hurt by the regime, albeit less than the Canadian Inuit. ${ }^{73}$ This is a strong argument against the presence of discriminatory purpose as we normally conceive it. To illustrate what I mean by 'discriminatory purpose as we normally conceive it', consider a protectionist tariff. The purpose of the tariff is precisely to discriminate, to put domestic and foreign producers in different positions, and thus to improve the fortunes of the domestic producers.

72 EC-Seal Products (Panel), para. 7.317.

73 As to the harm to Greenland Inuit, see http://arcticjournal.com/politics/494/eu-ban-blamed-rapiddecline-greenland-sealing. 
(And, of course, this sort of discriminatory purpose has an analogue in the mostfavored nation context.) But there is no reason to think that the EU seal products regime was motivated by discriminatory purpose of this sort. Even aside from the fact that the regime harmed the Greenland Inuit, there is no reason to think the goal of the measure was to put Greenland and Canadian Inuit in different positions. But even though there was no discriminatory purpose in this most traditional sense, there may still have been what we might call 'discrimination in respect of purpose'. Even if the regulator had no desire to create disparity between the Greenland and Canadian Inuit for its own sake, we could still think the regulator was more concerned to spare the Greenland Inuit from the full effects of the ban than to spare the Canadian Inuit. Indeed, the claim that there was this sort of 'discrimination in respect of purpose' is very plausible.

Even given this discrimination in respect of purpose, there is a further point to consider before we can conclude that there was a 2.1 violation. The ultimate question under TBT 2.1 is not whether there was discriminatory purpose, or discrimination in respect of purpose, but whether the measure is discriminatory. Let us hypothesize that the EU would have struck the balance between the value of indigenous culture and the value of seal welfare differently, and there would have been no IC exception at all, were it not for Denmark's championing of the Greenland Inuit. Even on this hypothesis, where the existence of the exception depends on special concern for Greenland, it could still be that the terms of the exception do not reflect greater concern with market access for the Greenland Inuit. This would be perfectly clear if the exception turned out to be de facto available to Canadian Inuit as well. But once we grasp the conceptual point that differential concern for certain Inuit communities does not necessarily produce a discriminatory exception, we should understand that that could be true even though the exception has a disparate impact, if there is a non-discriminatory explanation for that differential impact. And arguably there is. Apparently, the reason the Canadian Inuit did not take advantage of the IC exception was that the certification scheme requires segregation of Inuit and non-Inuit seal products (to make sure commercial seal products are not masquerading as Inuit seal products). Such segregation is practicable for Greenland seal products, because the Greenland Inuit seal hunt is large enough to support its own processing facility. The Canadian Inuit hunts are much smaller, and depend on processing facilities that also process commercially hunted seal, and segregation would be too costly. So the disparate impact of the IC exception seems to be explained by the difference in scale of the Greenland and Canadian hunts. The obvious analogue here is the required bond to insure payment of the cigarette tax in Dominican Republic-Cigarettes. Honduras objected that because they sold fewer cigarettes in the Dominican Republic than local producers did, the flat-rate bond created a greater burden on them, in the form of a higher per-cigarette cost. The Appellate Body rejected that argument, in effect saying that a disparate impact that was fully explained by a difference 
in scale was not a GATT III:4 violation. ${ }^{74}$ So far, then, there does not seem to be a convincing case that the EU seal products regime is un-evenhanded.

The Panel says darkly that the fact the Greenland Inuit can use the IC exception and the Canadian Inuit cannot is 'not merely an incidental effect of the application of the measure'. ${ }^{75}$ This sounds like saying the disparate impact was part of the EU's purpose. But all the evidence shows is that this disparate impact was not unanticipated. The Panel points out that the 2010 COWI Report, done for the Commission, predicted that only the Greenland Inuit would be able to take advantage of the Inuit exception, because only they operated on a scale that would make satisfying the certification requirements economically feasible. ${ }^{76}$ So the EU could anticipate the disparate impact. But that is not the same as being motivated to achieve it. Arguably, the EU merely chose the certification scheme that would most reliably prevent commercial seal products from masquerading as Inuit products, which was central to their concerns.

We quoted the Panel above saying: 'This [de facto exclusive access for Greenland Inuit] suggests in our view that the IC exception was not designed or applied in an even-handed manner so as to make the benefits of the exception available for all potential beneficiaries'. ${ }^{77}$ We have explained why this cannot mean that disparate impact by itself makes the exception un-evenhanded. But it might suggest instead that the EU regime was un-evenhanded because the EU made insufficient efforts to facilitate access for the Canadian Inuit. The Appellate Body in EC-Seal Products, citing US-Shrimp 21.5,78 complains specifically that the EU did not exert 'comparable effort' on behalf of the Canadian Inuit. ${ }^{79}$ But this case is not like US-Shrimp. In US-Shrimp, the United States did things for some countries that it did not do for the complainants: it negotiated more with them (and concluded one regional agreement); and it allowed them a longer phase-in time for the newly required technology. There is no evidence that the EU did anything to facilitate access for the Greenland Inuit (aside from Denmark's premature certification of some shipments, which the EU explains as a misunderstanding by Denmark of the new regulation). If the Panel thought that the EU should have done more for the Canadian Inuit, they give no indication of what they had in mind. Nor does the Appellate Body, beyond 'cooperative arrangements to facilitate the access of Canadian Inuit to the IC exception'. ${ }^{80}$ The Panel and Appellate Body almost suggest that the test of whether the EU has made enough effort is whether the Canadian Inuit can sell in the EU. But US-Shrimp 21.5 made it clear that the

74 Dominican Republic-Cigarettes, para. 96.

75 EC-Seal Products (Panel), para. 7.315.

76 Ibid., citing COWI, Study on Implementing Measures for Trade in Seal Products, Final Report (January 2010), p. 84.

77 Ibid., para. 7.317.

78 WT/DS58/AB/R (adopted 21 November 2001).

79 EC-Seal Products (Appellate Body), para. 5.337.

80 Ibid., para. 5.337. 
requirement of 'comparable effort' by the regulator does not mean that the complainant country's goods must be admitted. ${ }^{81}$

There are unquestionably certain ironies in the effects of the IC exception. The Greenland Inuit have access to the EU market, and the Canadian Inuit do not, even though the Greenland hunt is more commercialized than the Canadian Inuit hunt. Similarly, the Greenland Inuit have access to the EU market, and Canadian commercial hunters do not, even though the Greenland hunt is in some respects more inhumane than the commercial hunt. (The Greenland Inuit sometimes use nets to take seals, which is probably the most inhumane method of all.) But it should be remembered that even if the Greenland hunt is more commercialized than the Canadian Inuit hunt, it is still very different from the Canadian commercial hunt. The Greenland Inuit hunters work alone or in pairs; a much greater proportion of the seal products are consumed by the hunters or in their community; sealing represents a much higher proportion of the hunters' income; and the hunters have fewer alternative employment opportunities. Most importantly, the Greenland hunt is the continuation of a long cultural history, which is changing but still historically rooted and distinctive, and which is much more pervasive in the lives of the Inuit than seal-hunting is for Canadian commercial hunters. In sum, protecting the Greenland Inuit is not protecting a commercial hunt. As to the claim that the Greenland Inuit use more inhumane hunting methods than commercial hunters, this is largely or entirely attributable to the fact that the Inuit of necessity hunt all year round, and netting is the only practicable technique in the dark months. The harm to seals may be heightened, but so is the connection to the distinctiveness of Inuit culture. (Incidentally, it appears that the northern Canadian Inuit also use nets for similar reasons.) So, ironies, yes, but only because the world is complicated.

In sum, the facts relevant to 'evenhandedness' are messy. But if we assume that Canada has the burden of showing un-evenhandedness, as part of its general burden of proof under 2.1 (remember that the EC-Sardines Appellate Body imposed on Peru the burden of showing under TBT 2.4 that the Codex standard was effective and appropriate for the EU); ${ }^{82}$ and if we assume that the Panel has produced the best evidence available to show that the regulation is un-evenhanded, then I am not sure the Panel got the right result. Indeed, the evidence seems sufficiently inconclusive in either direction so that it might be that the right answer under TBT 2.1 is that Canada has not shown the measure is un-evenhanded, so the EU wins; and the right answer under the GATT XX chapeau is that the EU has not shown the measure is in compliance with the chapeau, so Canada wins.

81 US - Import Prohibition of Certain Shrimp and Shrimp Products, Recourse to Article 21.5 of the DSU by Malaysia, WT/DS58/AB/R (adopted 22 October 2001).

82 EC-Trade Description of Sardines, WT/DS231/AB/R (adopted 23 October 2002). 
The different burdens of proof would make the GATT more restrictive than the TBT in national treatment and most-favored nation cases.

Whatever we think about the right result on the facts, let us quickly summarize the conceptual and legal lessons from our discussion: (1) the evenhandedness inquiry is not simply about whether there is disparate impact (although there may be cases like US-Shrimp, involving specific types of disparate impact, where there can be un-evenhandedness without any illegitimate purpose); (2) even when there is no discriminatory purpose in the classic sense (exemplified by protectionism), there may still be what we have called 'discrimination in respect of purpose'; (3) the measure may be evenhanded, even if its adoption was motivated by a distinctive concern for particular beneficiaries; (4) anticipating a disparate impact is not the same as being motivated by it; (5) disparate impact that results from differences of scale is not necessarily a violation; and (6) there is no general requirement that the regulator take measures sufficient to alleviate disparate impact from an innocently motivated measure.

\subsection{Whether the EU seal products regime violates TBT 2.2}

TBT 2.2 requires that a measure not be more trade-restrictive than necessary to fulfill a legitimate objective. So under 2.2, the Panel was required to decide whether the EU's ban on seal products had a legitimate purpose, and if so, whether the same degree of fulfillment of that purpose could have been achieved with less trade restriction.

\subsubsection{Legitimate Regulatory Purpose: The Public Morals Purpose (and 'Extraterritoriality')}

The Panel finds that the basic purpose of the EU ban is a public morals purpose, reflecting EU citizens' moral opposition to the inhumane killing of seals, and their desire not to participate in such inhumane killing by purchasing products from inhumanely killed seals. And the Panel finds that this is a legitimate purpose under the TBT. This is the first time a WTO tribunal has found that "protecting public morals' is available as a justification under the TBT, but even so, that hardly seems like a ground-breaking conclusion. Given that the list of purposes in TBT 2.2 says it is not exclusive (and does not even include all the purposes mentioned in the TBT Preamble); and that the Appellate Body in US-Tuna II (Mexico) suggested looking to other WTO agreements for help in identifying legitimate purposes; ${ }^{83}$ and that both GATT XX and GATS XIV have 'public morals' clauses; it would be surprising if the Panel had held that protecting public morals, at least in the abstract, was not a legitimate purpose under the TBT. Canada and Norway do not seem to have objected to the idea that public morals are a legitimate purpose. 
With regard to how we establish the content of the Member's 'public morals', it is notable that the Panel does not appear to require polling evidence, or surveys, or the like. The evidence in the case did include some unsystematic public-comment evidence, of dubious probative value, collected by a consulting firm that studied the seals issue for the European Commission. ${ }^{84}$ But the Panel seems to have relied instead on the long history of more dispersed expressions of public concern, through NGO's and the like, and by legislative efforts in the various European countries and the EU itself (on related issues such as the killing of seal pups), which repeatedly characterized the issue as a moral or ethical one. This is completely appropriate. Especially in a democratic government (and we must assume by default for all WTO members), one of the roles of government is to construct and articulate public commitments, moral and otherwise (subject to certain limits of course), more concretely and distinctly than the population at large has the means to do. ${ }^{85}$ In US-COOL, the Panel was explicit that the legislature can establish a public purpose of providing country-of-origin information to consumers, without any evidence other than the regulation itself that consumers wanted such information. ${ }^{86}$

There are features of the EU seal products regime that cause some people to doubt the EU's commitment to avoiding animal suffering. (1) The ban was concerned only with seal products, ignoring the killing of farmed fox and mink for fur. But the conditions under which seal are killed are very different. (2) The exempted Greenland Inuit hunt was arguably especially inhumane, because it allowed netting in some circumstances. But as noted above, this was attributable to the year-round nature of a subsistence hunt. (3) Perhaps most troubling, the regime did not prevent the import of seal products for auctioning or other processing and re-export. This may be partly explained by the idea that prohibiting such 'inward processing' would probably not reduce the overall commerce in seal products (and hence the harm to seals) to nearly the extent that banning local purchases does. But the most persuasive argument for the genuineness of the EU's moral purpose is just this: Unless we think the seal ban was protectionism for fox and mink farmers (an argument the complainants apparently thought too

84 Of dubious probative value because most of the respondents were Anglophone, and most of those who favored the ban were from outside the EU. See Tamara Perisin (2013), 'Is the EU Seal Products Regulation a Sealed Deal? EU and ETO Challenges', International and Comparative Law Quarterly, 62: $373-405$, at 394 .

85 See Robert Howse and Joanna Langille (2012), 'Permitting Pluralism: The Seal Products Dispute and Why the WTO Should Accept Trade Restrictions Justified by Noninstrumental Moral Values', Yale Journal of International Law, 37: 367-432.

86 US-COOL (Panel), para. 7.649. The Appellate Body in US-COOL quoted this point from the Panel report, without expressly approving or disapproving; but in context the absence of disapproval suggests approval, since the Appellate Body expressed dissatisfaction with four other specific aspects of the Panel's discussion of the legitimacy of the US's purpose, even while generally upholding the Panel. US-COOL (Appellate Body), paras. 449-452. 
weak to rely on), there is simply no reason for the EU to have enacted the ban, even with all its limitations and exceptions, other than a concern for seals.

It is striking that the EU does not defend its seal products regime with the 'direct' argument that it protects seals, but only (or very predominantly) with the 'indirect' argument that it avoids moral outrage over seal suffering and participation in immorality by consumption. Presumably the EU was worried that protecting seals in Canada or Norway would not qualify as a legitimate purpose under the TBT or under GATT XX(b); whereas the moral outrage and the participationby-consumption, even with regard to 'foreign' seals, are located safely inside the EU. Relying on the public morals argument may have been a prudent litigation strategy, although it is worth remembering that the Appellate Body has never established the sort of territorial limitation the EU was presumably worried about. The Appellate Body set aside the territoriality issue in US-Shrimp with the observation that the relevant sea turtle populations were all of species that migrated through US territorial waters; ${ }^{87}$ and in US-Tuna II (Mexico), neither the Panel nor the Appellate Body found it necessary to discuss territoriality at all (although that might have been because the dolphins were on the high seas).

Canada and Norway's behavior is harder to understand. If the EU was sufficiently worried about territoriality issues to avoid claiming that they were protecting foreign seals, why didn't Canada and Norway positively assert that the EU could not protect seals in their countries, and then follow up with the argument that it should not be possible for the EU to evade that territorial limitation by shifting the focus from the seals to EU citizens' feelings about the seals? Of course, one can respond to a crude ipse dixit that, 'The EU can't protect seals in Canada and Norway', with the equally crude response, 'The moral feelings are in the EU'. But if there is any serious argument that establishes that the EU should not be able to protect foreign seals (not even using only the mechanism of limiting its own purchases), then that argument will very probably establish also that the EU should not be able to act on its feelings about foreign seals. In that case, appeal to public morals should not be allowed to avoid the territorial limitation.

So the crucial question is whether it would be legitimate for the EU to apply its consumption ban to Canadian and Norwegian seal products in order to protect Canadian and Norwegian seals. I think the answer is yes, it would be legitimate. Why should it not be? It is uncontroversial that a regulator may, as matter of fact, have a sincere concern for avoiding suffering by its domestic seals; and it is uncontroversial that the regulator may legally act on that concern. But any sensible regulator concerned to avoid suffering by its domestic seals would have exactly the same concern regarding foreign seals. The fact that the regulator acts to protect foreign seals as well as domestic is not by itself reason to think either that the regulation is motivated by national-origin preference (which is what TBT 2.1 and 
GATT I:1 and III:4 are designed to prevent), or that the regulation is more trade restrictive than necessary to protect the foreign seals (which is what TBT 2.2 is designed to prevent). To be sure, if the case were about different treatment of seal products, mostly from abroad, and fox or mink products, mostly domestic, then we would want to take a specially careful look at the sincerity of the concern for seals, and the reasons for not extending the same protection to fox and mink, to make sure there is no national-origin preference at work. But the complainants did not make that argument. Similarly, we may sometimes want to take a closer look at the regulator's assumptions about what degree of trade restriction is necessary to prevent harm occurring abroad and caused by behavior abroad, just because the regulator may be less well-informed about such cases. (Arguably US-Shrimp on TED's is an example of this.) But to my mind, none of these reasons for a close look justifies a flat ban on concern for foreign animals.

A different sort of argument is often suggested: that it is up to Canada (for example) to decide how Canadian seals shall be treated, and that the EU's applying its seal products ban to Canadian seal products is interfering in Canada's internal affairs. But the EU is not claiming any power to regulate seal-hunting in Canada directly. All it is doing is collectively refusing to purchase goods that it collectively does not want. Once we recognize the general right of governments to aggregate the preferences of their citizens, and to speak for their citizens on economic matters such as this, this is just the way the market works. Consumers, including countries as collective consumers, are not expected or required to buy what they do not want. Indeed, to force countries to buy what they do not want would be a serious interference in their internal affairs.

It may seem that my argument here is too strong. Can a Member refuse to buy foreign goods, or goods from some other particular Member, just because it doesn't want to buy foreign goods, or goods from that other Member? Of course not. But the reason is not any internal limitation on my argument. Countries should properly be free to act in this way, unless they have undertaken a commitment not to. But WTO Members have undertaken a general commitment not to engage in national-origin discrimination, either protectionism (except by tariffs) or preferences between foreign countries. ${ }^{88}$ A nation that wants to engage in protectionism should not join the WTO; a nation that wants to be able to discriminate against some particular other Member should take care to exclude WTO legal relations with that Member (as WTO Agreement Article XIII allows). Otherwise, each WTO Member has agreed not to exclude goods from any other Member on nationalorigin grounds, even if it regards that Member as a pariah. ${ }^{89}$

88 There are, of course, important exceptions in the most-favored nation context, for preferential trade areas and general systems of preferences for developing countries.

89 The hard case here, perhaps the case that requires an exception, is where a good-citizen Member radically changes its character, and becomes a systematic violator of international norms, like Burma becoming Myanmar. 
The question that has brought our discussion to this point is whether the EU can protect foreign seals. Protecting foreign seals could be done (indeed, if this were the only goal, it would be done best) by a simple ban, with no exceptions. Such a ban would not be a PPM; it would exclude seal products on the basis of properties fully ascertainable by inspection at the border. Even so, the issue about territorial restrictions on regulators' purposes bleeds over into the discussion of PPM's. So let us shift our focus for a moment to PPM's. Many people used to think that WTO membership entailed a general commitment not to choose among products on the basis of their production history (where that production history left no trace in the physical constitution of the product as it crossed the border). But the Appellate Body in US-Shrimp 21.5 established definitively that there is no such general commitment. In fact, I think much of the opposition to PPM's resulted from the fact that the examples that people used to talk about were country-based PPM's involving national-origin discrimination. Country-based PPM's are indeed forbidden, because of the broader commitment not to engage in national-origin discrimination that we have already discussed.

But not all the opposition to PPM's is directed at country-based PPM's. Even people who admit the permissibility of the US's revised shrimp-turtle regulation (either because they are persuaded, or perforce) raise other, more problematic, examples. The most-popular example is a hypothetical ban by a rich country on foreign goods made by workers paid less than the rich country's domestic minimum wage? (Notice this PPM is product-based.) This perennial example is powerful because no one wants to allow the minimum-wage PPM. Nor do I. But I also don't think the specter of the minimum-wage PPM is enough to justify prohibiting the US's shrimp-turtles PPM, or the EU's (non-PPM) seal products ban. The problem is how to distinguish them.

It is possible that we don't need a theoretical justification for the distinction at all. There has never been an actual minimum-wage PPM, and very likely the fact that such a PPM would be universally condemned as illegal, ignorant, and deeply unjust, is enough to deter any Member from enacting one. If such a PPM ever were enacted, it would presumably be defended on the ground that it protected exploited foreign workers. (To admit that it was designed simply to protect domestic workers against the low-wage foreign competition would be to admit protectionism outright.) But in fact, such a PPM is virtually certain to hurt the already vulnerable foreign workers it is nominally designed to benefit. Which means it is either disguised protectionism, or monumentally stupid. There is no general WTO principle forbidding stupidity. With regard to the minimum-wage PPM, however, we might say that the stupidity required to explain the PPM innocently is so extreme that the PPM is overwhelmingly likely to be protectionist, and hence it should be held illegal. This may be the best way to deal with the puzzle.

Still, there are other possibilities for distinguishing the minimum-wage PPM from the shrimp-turtle PPM or the seal products regime. For one thing, the minimumwage PPM is potentially much broader. Even if the minimum-wage PPM as actually 
adopted applies only to some particular product when made with 'underpaid' labor, it focuses on an aspect of production (the low wage) that is likely to be common to all productive enterprise throughout any affected exporting country. So it threatens to function like a country-based measure. That means we might justify a rule against such potentially broad PPM's as an implementation (admittedly crude, as rules often are) of the consent-based principle against nationalorigin discrimination. The potentially broad PPM also represents much more of a threat to seriously disturb the agreed balance of concessions. So we might justify a rule against such PPM's as an implementation (again crude, as rules often are) of GATT XXIII:1(b).

A different sort of point is that the foreign government is conceived of as speaking for its citizens (even though we know real governments often do not speak for all their citizens), in a way that it is not conceived of as speaking for its seals, its shrimp, or its turtles. Aside from the fact that seals and other fauna do not speak on political matters, a nation's animals are not even 'its' animals in the way that its citizens are 'its' citizens. So it may seem more disrespectful of the foreign country's autonomy to reject its view (which, at least by a legal fiction, is its citizens' view) of how its citizens are to be treated than to reject its view of how animals, some of which just happen to be found in its territory, should be treated. That is obviously not to say the animals are more important than the citizens; quite the reverse. ${ }^{90}$

I have no space for further discussion of 'extra-territoriality' and PPM's. (The reader may imagine a sigh of relief.) Although I have made some suggestions about how to distinguish the seal products ban (conceived as protecting foreign seals, not moral sensibilities), and similarly the shrimp-turtle PPM, from the minimum-wage PPM, I have no definite view at present about how best to do it. But that they should be distinguished, and treated differently by the WTO system, I have no doubt. So no damage was done by allowing the EU's end-run around the territoriality issue, although it should not have been necessary.

\subsubsection{Less restrictive alternative}

Once the Panel has decided that the EU's public morals purpose is a legitimate purpose, it remains to consider whether there is any less trade-restrictive alternative measure that would achieve the EU's purpose to the same degree as the actual measure. In brief, the complainants suggest various schemes to certify particular

90 A final point, that didn't quite fit anywhere. It is often objected that big-country PPM's (or regulations with 'extra-territorial' purposes) have disproportionate effects on small countries. That is true. But it is no less true of big country's non-PPM regulations with intra-territorial purposes. Big countries' decisions have big effects. That is a fact of economic life that the WTO does not attempt to correct for, except by specific provisions about special and differential treatment, transition periods, and the like. The general rules must be for all countries. The litigants here are the EU and Canada (big, rich, highly developed) and Norway (not so big, but rich and highly developed). 
shipments of seal products as the result of humane killing, whereas the EU claims that no effective system for monitoring is possible, given the physical conditions under which seal are hunted. The Panel's analysis is very fact-intensive, and it is sophisticated in considering possible unintended consequences of various suggested regimes, but it breaks no significant legal ground. In the end, the Panel concludes that the complainants have not identified any reasonably available, equally effective, less trade-restrictive alternative measure, so there is no 2.2 violation.

By finding no 2.2 violation, the Panel continued what is now a marked trend. There were challenges under TBT 2.2 in US-Clove Cigarettes, US-Tuna II (Mexico), US-COOL, and EC-Seal Products, and no final finding of a 2.2 violation in any of these cases. In US-Clove Cigarettes, the Panel found a 2.1 violation but no 2.2 violation, and Indonesia did not appeal the 2.2 finding. In US-Tuna II (Mexico), the most striking case, the Panel found a 2.2 violation and no 2.1 violation, and the Appellate Body reversed on both counts, finding a 2.1 violation but no 2.2 violation. In $U S-C O O L$, the Panel found a 2.2 violation (as well as a 2.1 violation) and was again reversed on the 2.2 violation. And then we have the EC-Seal Products Panel, which finds a 2.1 violation but no 2.2 violation. No wonder.

\subsection{Whether the EU seal products regime violates TBT 5.1.2 and 5.2.1}

This is the first report dealing with TBT Article 5 on conformity assessment procedures [CAP's]. There were complaints under 5.1.2, first sentence, which requires that a CAP not constitute an 'unnecessary obstacle to international trade'; 5.1.2, second sentence, which requires that a CAP not be 'more strict or be applied more strictly than necessary' to give adequate assurance of conformity; and 5.2.1, which requires that a CAP be undertaken and completed 'as expeditiously as possible'. In general, the Panel (no doubt correctly) regarded these provisions as applying, mutatis mutandis, to procedures for accrediting certifying bodies, as well as to the actual process of product certification.

Under 5.1.2, first sentence, Canada and Norway had two grounds of complaint. By way of factual background, the EU ban on shrimp products entered into force on 20 August 2010. The EU at no time had a governmental body competent to certify products; and the procedures for accrediting private bodies to issue certifications were announced only on 17 August 2010. Accordingly, it was impossible in practice for any certifying body to be accredited until some time after the ban became effective. So for some period after the ban became effective, it was not possible for even products that qualified under the exceptions to enter the EU market.

The complainants argued first that the EU was required to guarantee that trade in qualifying products was possible, so that the $\mathrm{EU}$ was required to have some $\mathrm{EU}$ agency that could certify products, until there were accredited private certifying bodies (or indefinitely, if no private bodies applied for, or were granted, 
certification). The Panel rejected this claim with no more argument than the observation that Article 5 allows a system of third-party accreditation, ${ }^{91}$ which does not seem to fully dispose of the question what happens if no private bodies step up. On the other hand, the Panel, again without much argument, held that the EU did create an unnecessary obstacle to trade by creating a situation in which there was no possibility of certification by the time the ban took effect. ${ }^{92}$ These holdings, both ipse dixit's, may seem to point in opposite directions, but there is no logical inconsistency. The upshot is that the EU is not required to guarantee that trade is possible on the date the ban becomes effective, or ever (by creating a government certifying agency); but it must not guarantee that trade is not possible on the date the ban becomes effective (by having no procedure for private certifying bodies to become accredited in time).

It is not clear the Panel was right to find that the late publication of the accreditation procedures created an 'unnecessary obstacle'. In the absence of any explanation for why the EU was so late, it surely seems that the EU behaved less than ideally. But it seems doubtful that the impossibility of certification when the ban took effect was an 'obstacle' to trade. The only 'obstacle' to trade was the ban itself (and the Panel had found in its 2.2 discussion that this obstacle was not unnecessary). ${ }^{93}$ The IC exception removes an obstacle, for some traders; so it seems that failure to have the exception is only failure to remove an obstacle, and not an obstacle in itself. Consider some hypotheticals. There would be no violation if the EU had simply adopted a ban of seal products, with no thought of any exception. There would also be no violation if the EU thereafter decided that it wanted to have an IC exception, and added one. But the Panel is saying in effect that because the EU knew before it promulgated the ban that it wanted an IC exception, it could not enact the ban (which is fully justified by its own public morals purpose) without a functioning IC exception in place. And in the actual case, it says that without any discussion of what administrative factors might have accounted for the EU's belated formulation of the certification regime. This seems a curious jump.

It might seem that the argument here is too strong, that it would mean that failure to have a functioning exception could never be an unnecessary obstacle, which seems wrong. But the argument does not have that consequence. Consider a different sort of case. Suppose the EU requires that milk be safe, and has a CAP for certifying safety. In operative terms, this regime will function as a ban on milk, with an exception for milk certified safe. But this is different from the EC-Seal Products case, because here the exception is required by the health purpose of the ban.

91 EC-Seal Products (Panel), para. 7.524.

92 Ibid., para. 7.528.

93 Lest there be doubt, the Panel observed in the 2.2 discussion that the presence of the exceptions reduced the effect of the ban, which makes it less clear that the ban was 'necessary' (e.g., para. 7.460). So it would have been even clearer that a ban without exceptions was 'necessary'. 
Without the exception for safe milk, the ban on milk would be unnecessarily traderestrictive, by reference to its health purpose. In EC-Seal Products, however, a flat ban of seal products would be fully justified by its morals purpose. The IC exception is justified by a different purpose from the purpose of the ban. Hence, it is a matter of legislative grace. In which case, it seems it is not an 'obstacle' for it not to be available in a timely manner. ${ }^{94}$

As to 5.1.2, second sentence, the Panel found that that sentence required it to consider whether the chosen CAP, once in force, would be stricter than necessary; and it held there was no violation. The very plausible reasoning tracked the Panel's 2.2 discussion; and so we might add this decision to the trend of not finding violations of the 2.2 type. Finally, under 5.2.1, with regard to the question whether the process for accrediting certifying bodies, once under way, operated 'as expeditiously as possible', the Panel held that it had insufficient evidence to find a violation. In connection with one application for accreditation from 11 Swedish county administrative boards, there was an initial exchange in which the EU Commission listed deficiencies in the application, and the boards responded with new documentation. It then took the Commission over 14 months to decide this new documentation was sufficient, and accredit the boards. The Panel said this did not seem 'expeditious'. ${ }^{95}$ But they later said that the complainants 'have not provided any specific argument as to how the CAP was not conducted in the concerned instances as expeditiously as possible'; and so they found no violation. ${ }^{96}$ Perhaps their idea was that one egregious case (the other case they discussed was slow, but not so extreme) does not make a violation of a provision aimed at a systematic fault.

\subsection{Coda: does the TBT matter?}

In EC-Seal Products, the Panel focused on the TBT violations; its discussion of GATT was parasitic on the TBT discussion, and essentially an afterthought. The Appellate Body held that the EU seal products regime was not a technical regulation at all ... and then got the same result under the GATT, just as the Panel had. This is an apt occasion to wonder whether the TBT is actually making any difference. The two distinctive obligations in TBT Article 2, which is the core of the Agreement, are the obligation to use least trade-restrictive regulatory means in 2.2 , and the conditional obligation to use international standards in 2.4. As we pointed out above, the tribunals have shown a notable reluctance to find 2.2 violations. There has been one holding of a violation of 2.4, in EC-Sardines, but it seems

94 I have not considered whether there is some other way to argue that the EU's behavior is illegal. It may have disappointed some producer expectations; but even that is not clear. Producers could see some time in advance that the exception was not going to be available at the time the ban became effective, and we are given no evidence about how that 'some time in advance' compares to the time scale on which they made production decisions.

95 Ibid., para. 7.577.

96 Ibid., para. 7.579 (emphasis in original). 
very likely that the same result could have been reached under TBT 2.1, and under GATT III:4. Once the Appellate Body held in EC-Sardines that the burden was on the complainant Member to prove that the international standard would be 'effective' and 'appropriate' for use by the respondent Member, they effectively guaranteed that whenever there is a 2.4 violation, there will be a strong case for a GATT violation (of III:4, or I:1, as relevant), assuming there is disparate impact. Even if there were no 2.4 and no obligation to use the international standard, the international standard would still, by hypothesis, describe an effective and appropriate less trade restrictive alternative measure. The most distinctive feature of TBT 2.2 and 2.4 is that they do not require disparate impact as part of establishing a violation. But so far, the facts of all eight TBT cases (including the cases in which no TBT issues were decided other than issues about what was a technical regulation) have involved disparate impact. ${ }^{97}$ That is not surprising. It is cases involving disparate impact that complainants are most likely to care strongly about, and most likely to be willing to spend resources litigating. What all this means is that the TBT may not matter much in practice. Perhaps, heretical thought, the Members should abolish it, to save litigation resources and focus litigation better on the real issues. ${ }^{98}$

\section{Conclusion}

The EC-Seal Products Panel decision dealt with a variety of specific questions under the TBT. In the process, it also dealt more generally with the balance between a nation's right to regulate in support of its citizens' moral concerns and trading partners' rights to market access. The Panel did not settle on any of the 'bright lines' that have been suggested to limit regulation. It is possible to wish that the Panel had laid down some bright lines, to give more specific guidance about what regulations will be upheld or invalidated in the future, and to provide stronger safeguards against protectionism. Or it is possible to think the Panel gave about as clear guidance as is desirable or possible for this sort of case, and additional bright lines would unduly restrict governments' ability to pursue innocent and legitimate purposes.

Whether one welcomes the Panel's analysis or sees it as alarming depends on how one perceives the prevalence of protectionist motives and the sturdiness of other safeguards against protectionism. Given the split of opinion and the range of cases in which these questions might arise, we can expect the discussion to be prolonged.

97The one case we have had no occasion to mention is EC-Protection of Trademarks and Geographical Indications for Agricultural Products and Foodstuffs (Australia), WT/DS290/R (adopted 20 April 2005).

98 It would be an argument for keeping the TBT if the TBT Committee has been a useful institution (a possibility on which I express no view). But it is not clear that we actually need the TBT to get any of the benefits we now get from the TBT Committee. 